\title{
Impact Properties of Slack-Quenched Alloy Steels
}

\author{
Melvin R. Meyerson and Samuel J. Rosenberg
}

\begin{abstract}
A method was developed for slack quenching impact specimens so as to produce uniform and accurately controlled hardnesses and microstructures at any location in the cross section. Steels of the $81 x x$ type, without and with boron, and varying in hardenability, were studied to evaluate the effect of slack quenching upon the impact properties.

Slack quenching was shown to be detrimental to the impact properties of the steels. The injurious effects were found to be dependent on the carbon and alloy content of the steels, the degree of slack quenching, and the amount of tempering.

When any two steels were slack quenched to the same hardness, the higher carbon lower alloy steel had impact properties inferior to those of the lower carbon higher alloy steel. Tempering usually improved the properties of both and reduced the differences between them.

The higher the hardness to which any steel was slack quenched, the lower were its impact properties. When tempered to the same hardness, however, the steel originally slack quenched to the higher hardness had the better impact properties.
\end{abstract}

\section{Introduction}

Despite the fact that slack-quenched structures are frequently found in heat-treated steels, quantitative evaluation of the effect of slack quenching upon the mechanical properties of such steels has never been adequately defined. This is due, not to lack of recognition that such data are needed, but rather to the lack of heat-treating techniques that can accurately control the desired slack-quenched microstructures.

In an effort to overcome this deficiency, many researches have evaluated the effect of nonmartensitic decomposition products of austenite upon the mechanical properties of various steels. With but one exception, the amount and nature of the nonmartensitic products have been controlled by the use of isothermal transformation techniques. Although much excellent work of this nature has been carried out, the results obtained are not necessarily indicative of the properties of slack-quenched steels in which the amount and nature of the nonmartensitic products may vary considerably, depending upon size effects and the rate of cooling. The reported exception is the work of Vajda and Busby $[1,2],{ }^{1}$ who end quenched 7 -in. diameter rounds and tested specimens cut from sections parallel to the quenched ends. Although the technique developed was new and useful, it suffers from two disadvantages in that the mass of steel needed for development of the slack-quenched specimens is considerable and the cross sections of the test specimens so obtained cannot be uniform because finite differences in cooling rates must exist. These authors attempted to minimize the latter by using subsize specimens, but the fact remains that finite changes in cooling rate, with corresponding differences in microstructure, exist over the cross sections of the specimens so obtained.

The project described in this paper is concerned with the effect of slack quenching upon the impact properties of steels, data which were desired by Watertown Arsenal. The problem posed was: Given a pair of selected steels whose Jominy (end

\footnotetext{
1 Figures in brackets indicate the literature references at the end of this paper.
}

quench) hardenability curves crossed each other, the intersection of these curves represent equal hardness, obtained at equal cooling rates. The resulting microstructures, however, could be expected to be dissimilar. Information was desired as to the effect such slack quenching would have upon the impact properties of the steels involved.

The present paper describes a simple technique for accurately controlling the hardness and microstructure of slack-quenched impact specimens, and gives the results of the effect of slack quenching, both with and without tempering, upon the impact properties of a series of $81 x x$ steels, both without and with boron. Specifically, a comparison is made between the structure and impact properties of various pairs of steels, slack quenched to the hardness corresponding to a point of intersection of their Jominy curves (the steels were intentionally designed to give this intersection). A similar comparison is made of the structures and impact properties of pairs of the same steels treated with boron and slack quenched to obtain a hardness equal to that at the point of intersection of their Jominy curves. A third comparison is made between pairs of the boronfree and boron steels. A few supplementary tests were made on some of the same steels as fully hardened and then tempered to the same hardness levels as the slack-quenched steels, or the slackquenched and tempered steels.

\section{Experimental Steels}

\subsection{Design, Melting, Fabrication, and Analyses}

Using 8140 as a base, it was planned to study the effects of slack quenching upon similar alloy steel of higher and lower carbon, with the alloy content so modified that the Jominy hardenability curves of the various steels intersect. Jominy hardenabilities were calculated in accordance with the procedure described in the Metals Handbook [3], using the values and multiplying factors given therein. For purposes of calculation, an ASTM grain size number of 8 was assumed for all steels. The validity of this 
TABLE 1. Chemical compositions and hardening temperatures of the steels

\begin{tabular}{|c|c|c|c|c|c|c|c|c|c|c|c|}
\hline \multirow{2}{*}{ Steel No. } & \multicolumn{10}{|c|}{ Percent by weight } & \multirow{2}{*}{$\begin{array}{c}\text { Hardening } \\
\text { tempera- } \\
\text { ture }\end{array}$} \\
\hline & C & Mn & $\mathrm{P}$ & $\mathrm{s}$ & $\mathrm{Si}$ & $\mathrm{Ni}$ & $\mathrm{Cr}$ & Mo & $\mathrm{Al}$ & B & \\
\hline $\begin{array}{l}\text { BR-27 } \\
\text { BR-28_..- }\end{array}$ & 0.49 & 0.87 & - & 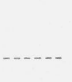 & 0.33 & 0.22 & 0.30 & 0.08 & 0.05 & $\left\{\begin{array}{r}\text { None } \\
0.0018\end{array}\right.$ & $\begin{array}{l}{ }^{\circ} F \\
1,500\end{array}$ \\
\hline $\begin{array}{l}\text { BR-21 } \\
\text { BR-22_... }\end{array}$ & .46 & .91 & 0.005 & 0.029 & .28 & .24 & .35 & .10 & .06 & $\left\{\begin{array}{r}\text { None } \\
0.0017\end{array}\right.$ & 1,500 \\
\hline $\begin{array}{l}\text { BR-17_... } \\
\text { BR-18_.- }\end{array}$ & .44 & .87 & .005 & .026 & .27 & .32 & .46 & .16 & .07 & $\left\{\begin{array}{r}\text { None } \\
0.0019\end{array}\right.$ & 1,550 \\
\hline $\begin{array}{l}\text { BR-1.... } \\
\text { BR-2 }\end{array}$ & .38 & .44 & - n-... & -.-.-- & .08 & .30 & .42 & .13 & .06 & $\left\{\begin{array}{r}\text { None } \\
0.0022\end{array}\right.$ & 1,550 \\
\hline $\begin{array}{l}\mathrm{BR}-25 \ldots \\
\mathrm{BR}-26 \ldots\end{array}$ & .30 & .75 & -.-.- & --.-- & .28 & .52 & .68 & .15 & .05 & $\left\{\begin{array}{l}\text { None } \\
0.0021\end{array}\right.$ & 1,600 \\
\hline $\begin{array}{l}\text { BR-19 } \\
\text { BR }-20 \ldots\end{array}$ & .28 & .90 & .006 & .027 & .30 & .45 & .62 & .21 & .08 & $\left\{\begin{array}{r}\text { None } \\
0.0017\end{array}\right.$ & 1,600 \\
\hline $\begin{array}{l}\text { BR-23_. } \\
\text { BR-24_.. }\end{array}$ & .19 & .96 & .005 & .024 & .33 & .63 & .86 & .32 & .08 & $\left\{\begin{array}{r}\text { None } \\
0.0020\end{array}\right.$ & 1,625 \\
\hline $\begin{array}{l}\text { BR-29 } \\
\text { BR-30 }\end{array}$ & .19 & .95 & -..... & --..- & .33 & .68 & .86 & .19 & .06 & $\left\{\begin{array}{c}\text { None } \\
0.0024\end{array}\right.$ & 1,625 \\
\hline
\end{tabular}

assumption was borne out by subsequent metallographic examinations.

Beginning with the calculated hardenability of 8140, using the composition corresponding to the middle of the range $(0.41 \% \mathrm{C}, 0.85 \% \mathrm{Mn}, 0.28 \% \mathrm{Si}$, $0.30 \% \mathrm{Ni}, 0.43 \% \mathrm{Cr}, 0.11 \% \mathrm{Mo}$ ), hardenability curves were calculated for steels at carbon levels of 0.20 percent, 0.30 percent, and 0.50 percent with manganese and silicon constant at the midlevel of 8140 and with nickel, chromium, and molybdenum increased for the two lower carbon levels and decreased for the higher carbon steel. In changing the alloy content, the Ni-Cr-Mo ratio was maintained constant at the same ratio as exists in 8140 . Several curves were calculated for each carbon level, using different totals of alloy content, and from these curves four steels varying in carbon content were selected for melting.

All steels were melted in an induction furnace, using a magnesia crucible. Each melt was $150 \mathrm{lb}$, deoxidized with aluminum (2 lb/ton) and split two ways during pouring with boron (as ferroboron) added in the ladle to one-half of each melt. The steels were poured into hot-topped split molds 131/2 in. high, $2 \frac{3}{4}$ in. square at the bottom and $3 \frac{3 \%}{4}$ in. square at the top. A cast Jominy specimen also was poured from each split heat. The ingots, containing about $45 \mathrm{lb}$ of usable metal, were either surface ground or cleaned by tumbling and then hot rolled to $5 / 8$ in. plate. A 4 in. length (for Jominy specimens) was sheared off when the plate thickness reached $1 \frac{11}{4} \mathrm{in}$. All plates were normalized at $1,650^{\circ} \mathrm{F}$ before being machined into specimens.

The compositions of the steels are listed in table 1. Chemical analyses were made only on samples taken from the boron-treated halves of the split heats.

A metallographic examination was made of each boron-free steel shown in table 1. Photomicrographs of these (except BR-29) in the hot-rolled and nor- malized condition are shown in figure 1. Ferrite banding was absent or very slight, BR-1 being the worst in this respect. In three of the steels $(\mathrm{BR}-17$, 19 , and 23), the carbides were partially spheroidized.

\subsection{Hardenability}

At least one Jominy hardenability test was made on each steel, both as cast and normalized, and as hot rolled and normalized. The proper hardening temperature, based on carbon content, was used for each steel in making the Jominy tests, and in all subsequent hardening. These temperatures are shown in the last column of table 1 . The addition of boron resulted in improved hardenability in each case, and the amount of improvement varied with the composition of the steel (figs. 2 and 3). Generally, those steels that had the lowest carbon content were improved the most by the addition, an exception being $\mathrm{BR}-1$, which was low in manganese and silicon. The results obtained on both the cast and wrought specimens of the same steel agreed closely. However, the curves did not, in general, coincide with the computed curves; the experimental curves indicated lower hardenability than was computed (fig. 4).

The ASTM procedure for making Jominy hardenability tests [4] specifies that the hardenability test bar be quenched from the proper hardening temperature for that steel. The graph paper supplied by ASTM for plotting the results of hardenability tests indicates that a specific cooling rate (at $1,300^{\circ} \mathrm{F}$ ) is obtained at each increment of distance from the quenched end. Actually this cooling rate can be influenced somewhat by the hardening temperature. However, because the range of hardening temperatures used in the present study was relatively small $\left( \pm 65^{\circ} \mathrm{F}\right)$, it is believed that variations in cooling rate, due to the different quenching temperatures used, were insignificant. 


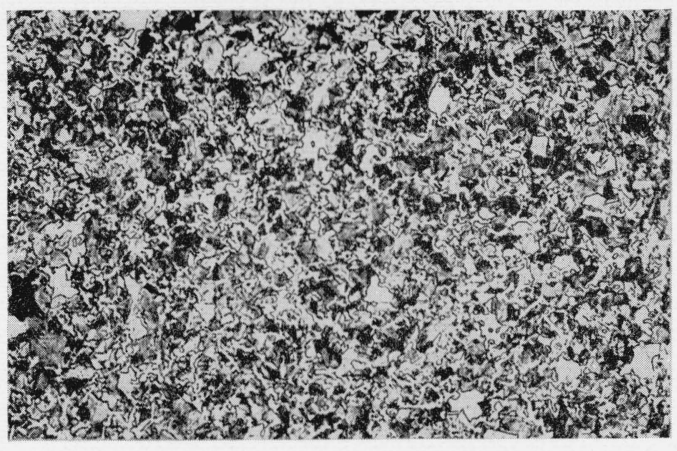

BR-27 $(0.49 \% \mathrm{C})$

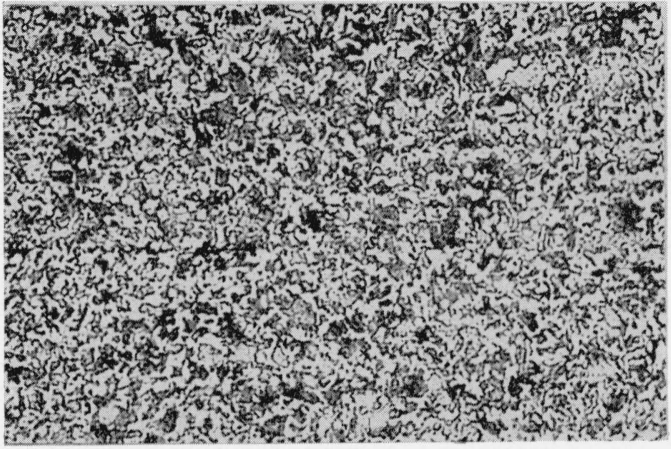

$$
\text { BR- } 17 \quad(0.44 \% \mathrm{C})
$$

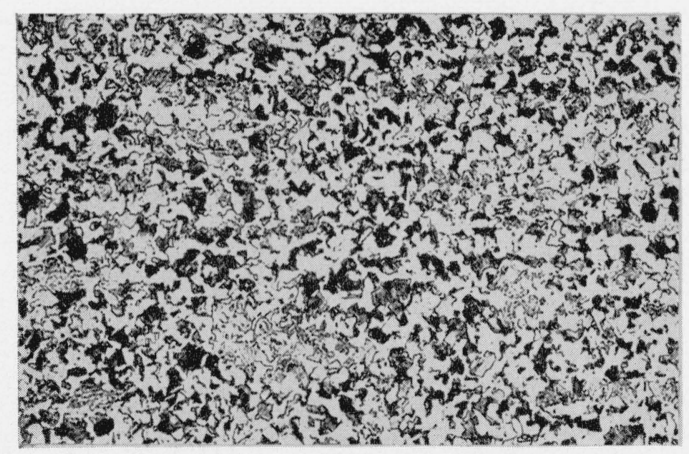

$$
B R-25 \quad(0.30 \% \mathrm{C})
$$

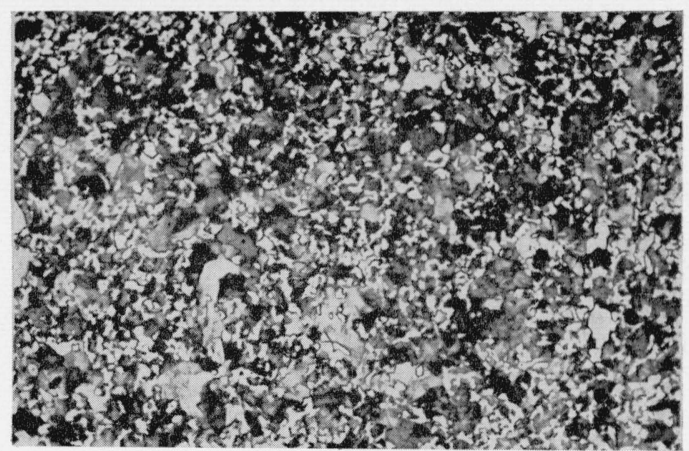

BR-2I $(0.46 \%$ C $)$

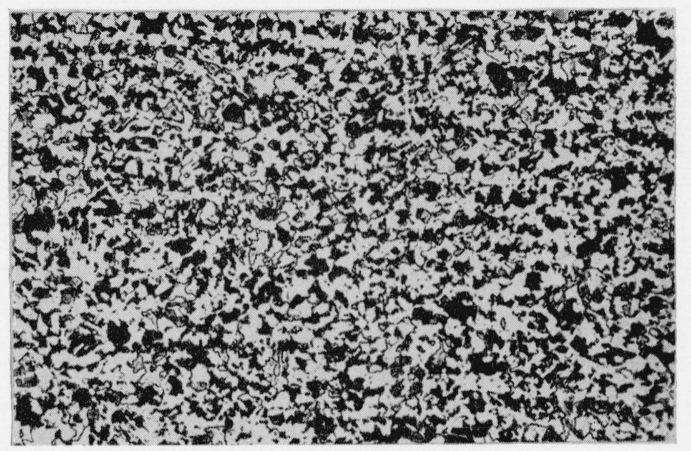

$B R-1 \quad(0.38 \% C)$

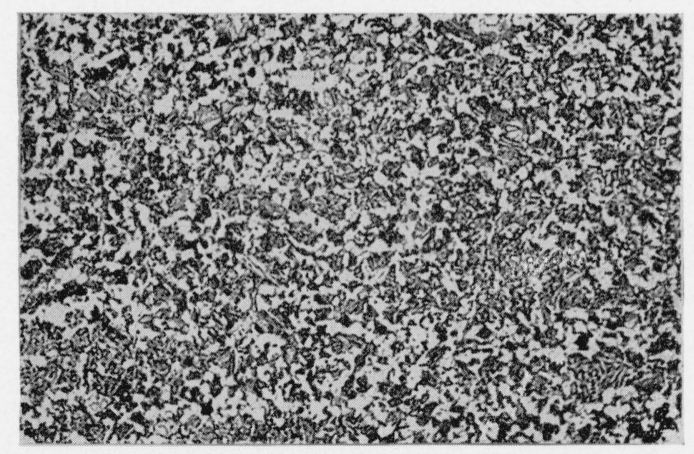

$B R-19(0.28 \% C)$

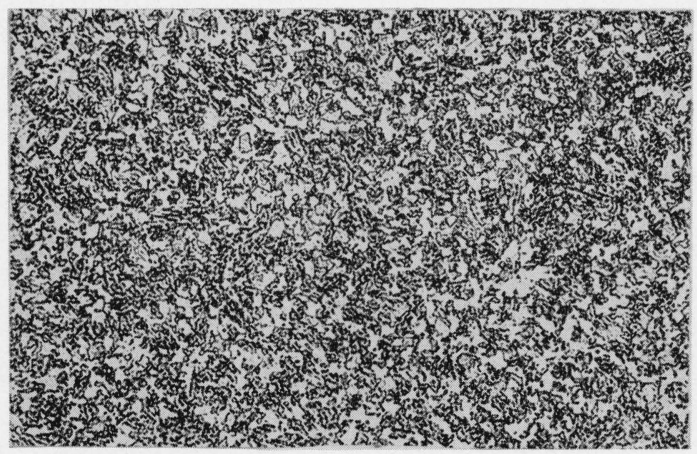

$B R-23(0.19 \% C)$

Figure 1. Structures of boron-free steels.

Hot rolled to $5 / 8 \mathrm{in}$. plate and then normalized ( $1 \mathrm{hr}$ at $1,650^{\circ} \mathrm{F}$, air cooled). Etched in $1 \%$ nital. $\times 100$. 


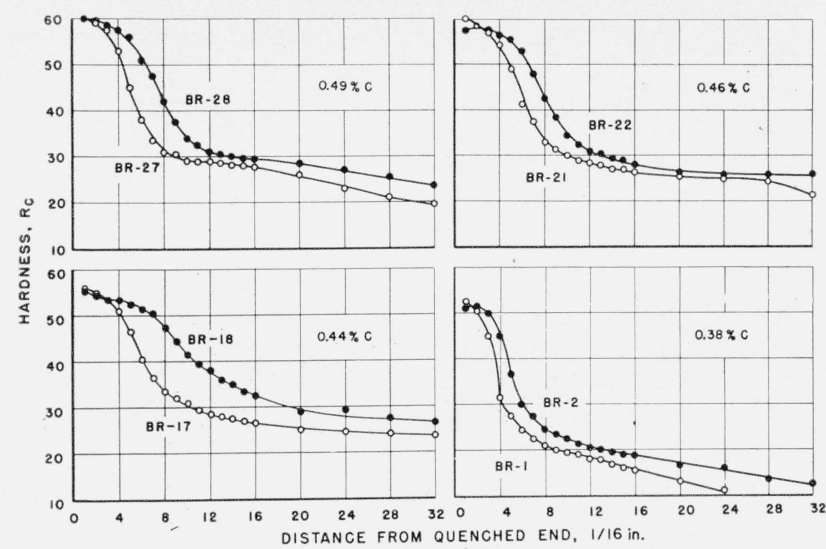

FIGURE 2. Hardenability curves for split heats of steels as hot rolled and normalized.

Numbers on curves are the steel identification numbers. Odd-numbered steels are the base steels; even-numbered steels are the boron-treated splits.

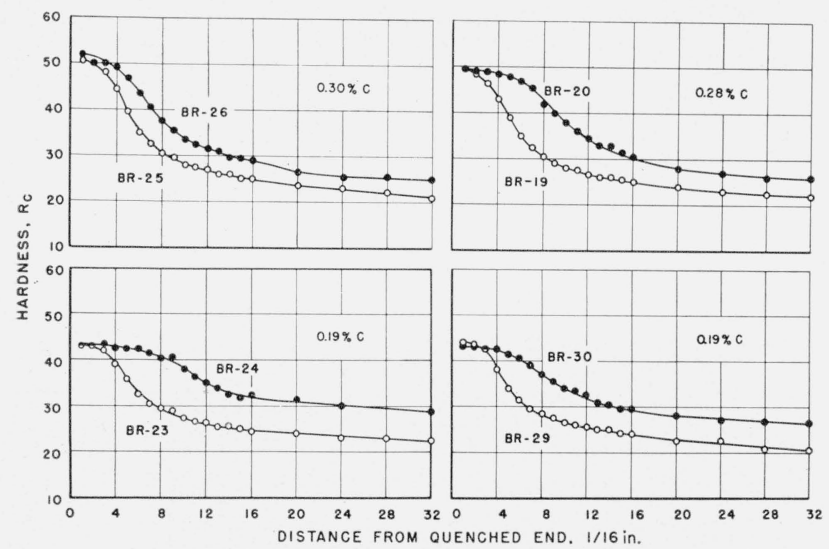

Figure 3. Hardenability curves for split heats of steels as hot rolled and normalized.

Numbers on curves are the steel identification numbers. Odd-numbered steels are the base steels; even-numbered steels are the boron-treated splits.

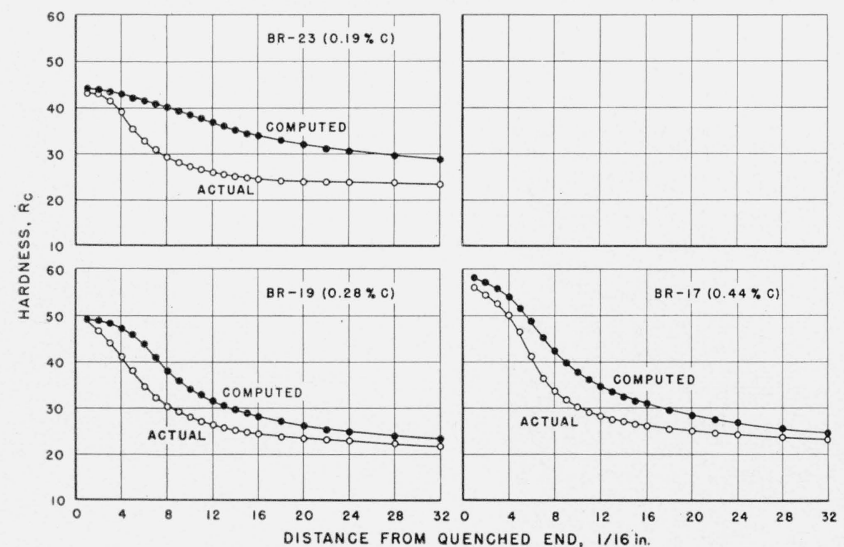

Figure 4. Comparison of computed and actual hardenabilities of some of the steels.
In order to determine accurately the points of equal hardness at equal cooling rates between any two or more steels, all of the hardenability curves were plotted on an expanded scale as a single master graph, and the intersections of the various curves determined. For practical purposes, and because of the limits of accuracy in hardness testing, curves approaching each other within $\pm 1 / 2 R_{c}$ were considered as intersecting even if no actual intersection occurred. Only intersections at a hardness level of $30 \mathrm{R}_{\mathrm{c}}$ or higher were used. Four such hardenability curves, taken from the master graph, are shown in figure 5.

Based on carbon content and provided that the hardenability curves cross each other only once, there are six possible intersections of two curves each, for the boron-free steels, and six for the boron steels. There are only six possible intersections of two curves each for the boron-free steels versus the boron steels, because the presence of boron always improved the hardenability. It was found that none of the curves of the higher carbon steels containing boron intersected those of the lower carbon steels without boron. For convenience, each combination will be referred to as follows:
Code $\mathrm{A}-0.50 \% \mathrm{C}$ and $0.41 \% \mathrm{C}$
Code $\mathrm{B}-0.41 \% \mathrm{C}$ and $0.30 \% \mathrm{C}$
Code $\mathrm{C}-0.30 \% \mathrm{C}$ and $0.20 \% \mathrm{C}$
Code $\mathrm{D}-0.50 \% \mathrm{C}$ and $0.30 \% \mathrm{C}$
Code $\mathrm{E}-0.41 \% \mathrm{C}$ and $0.20 \% \mathrm{C}$
Code $\mathrm{F}-0.50 \% \mathrm{C}$ and $0.20 \% \mathrm{C}$

Although 18 combinations of one intersection were theoretically possible, only 15 could be obtained, as

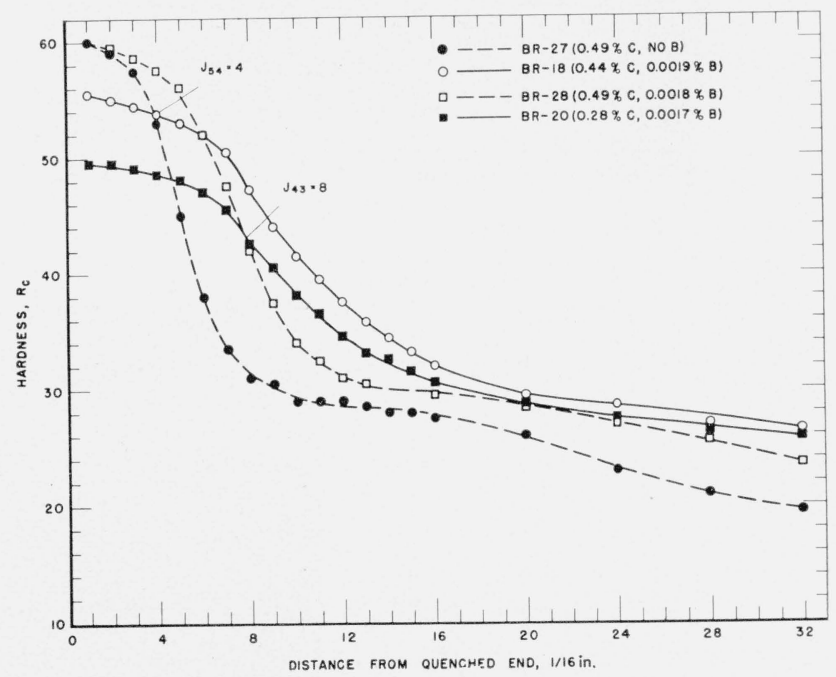

FIGURE 5. Jominy hardenability curves for four of the steels.

Intersections of the curves indicate points of equal hardness at equal cooling rates. 
indicated in table 2. In order to obtain this many combinations, it was necessary to utilize steel BR-1, which had a low manganese and silicon content.

All of the steels were examined metallographically after being slack quenched to the proper hardness level at which they were to be tested, and the microstructures at each of the hardness levels noted in table 2 are shown in figures 6,7 , and 8 . The structures varied according to carbon and alloy content, and the hardness levels to which the steels were slack quenched, and the two steels of any pair quenched to the same hardness usually varied in structure, often markedly. Steels quenched to the higher levels of hardness contained appreciable amounts of martensite, some bainite, and occasionally small amounts of pearlite and sometimes even traces of ferrite. As the slack-quenched hardness decreased, more bainite, pearlite, and ferrite appeared in the microstructures. The relative amounts of the various constituents were influenced by the carbon content in that the lower carbon steels had more martensite and bainite, and less pearlite, when quenched to moderate levels of hardness, than did the higher carbon steels. This difference in any pair of steels became more marked as the differential in carbon content increased.

TABLE 2. Selected intersections $\left( \pm 1 / 2 R_{c}\right)$ of Jominy hardenability curves

\begin{tabular}{|c|c|c|c|}
\hline $\begin{array}{c}\text { Combi- } \\
\text { nation } \\
\text { code }\end{array}$ & $\begin{array}{l}\text { Steel numbers and percent carbon } \\
\text { content }\end{array}$ & $\begin{array}{c}\text { Hardness at } \\
\text { intersection, } \\
\mathrm{R}_{0}\end{array}$ & $\begin{array}{c}\text { Distance } \\
\text { from } \\
\text { quenched } \\
\text { end, } 1 / 16 \mathrm{in} .\end{array}$ \\
\hline \multicolumn{4}{|c|}{ Boron-free steel versus boron-free steel } \\
\hline $\begin{array}{l}\mathrm{A} \\
\mathrm{B} \\
\mathrm{C} \\
\mathrm{D} \\
\mathrm{E} \\
\mathrm{F}\end{array}$ & $\begin{array}{l}\text { BR-27 }(0.49 \mathrm{C}) \text { and BR-17 }(0.44 \mathrm{C}) \\
\text { BR-1 }(0.38 \mathrm{C}) \text { and BR-25 }(0.30 \mathrm{C}) \\
\text { BR-19 }(0.28 \mathrm{C}) \text { and BR-23 }(0.19 \mathrm{C}) \\
\text { BR-27 }(0.49 \mathrm{C}) \text { and BR-25 }(0.30 \mathrm{C}) \\
\text { Not obtained } \\
\text { Not obtained }\end{array}$ & $\begin{array}{l}46 \\
49.5 \\
30 \\
33 \\
-\end{array}$ & $\begin{array}{l}5 \\
3 \\
8 \\
7 \\
-1\end{array}$ \\
\hline
\end{tabular}

\begin{tabular}{|c|c|c|c|}
\hline \multicolumn{4}{|c|}{ Boron-free steel versus boron steel } \\
\hline $\begin{array}{l}\text { A } \\
\text { B } \\
\text { C } \\
\text { D } \\
\text { E } \\
\text { F }\end{array}$ & $\begin{array}{l}\text { BR-27 }(0.49 \mathrm{C}) \text { and BR-18 }(0.44 \mathrm{C}) \\
\text { BR-17 }(0.44 \mathrm{C}) \text { and BR-26 }(0.30 \mathrm{C}) \\
\mathrm{BR}-19(0.28 \mathrm{C}) \text { and BR-24 (0.19C) } \\
\mathrm{BR}-21(0.46 \mathrm{C}) \text { and BR-20 }(0.28 \mathrm{C}) \\
\mathrm{BR}-17(0.44 \mathrm{C}) \text { and BR-30 }(0.19 \mathrm{C}) \\
\mathrm{BR}-21(0.46 \mathrm{C}) \text { and BR-24 }(0.19 \mathrm{C})\end{array}$ & $\begin{array}{l}54 \\
48 \\
42 \\
48 \\
40 \\
43\end{array}$ & $\begin{array}{l}4 \\
5 \\
4 \\
5 \\
6 \\
5\end{array}$ \\
\hline \multicolumn{4}{|c|}{ Boron steel versus boron steel } \\
\hline $\begin{array}{l}\mathrm{A} \\
\mathrm{B} \\
\mathrm{C} \\
\mathrm{D} \\
\mathrm{E} \\
\mathrm{F}\end{array}$ & $\begin{array}{l}\text { BR-18 }(0.44 \mathrm{C}) \text { and BR-22 }(0.46 \mathrm{C}) \\
\text { BR-18 }(0.44 \mathrm{C}) \text { and BR-20 }(0.28 \mathrm{C}) \\
\text { BR-24 }(0.19 \mathrm{C}) \text { and BR-26 }(0.30 \mathrm{C}) \\
\text { BR-20 }(0.28 \mathrm{C}) \text { and BR-28 }(0.49 \mathrm{C}) \\
\text { Not obtained } \\
\text { BR-30 }(0.19 \mathrm{C}) \text { and BR-28 }(0.49 \mathrm{C})\end{array}$ & $\begin{array}{l}52.5 \\
30 \\
43 \\
43 \\
33\end{array}$ & $\begin{array}{r}6 \\
18 \\
6 \\
8 \\
12\end{array}$ \\
\hline
\end{tabular}

CODE A

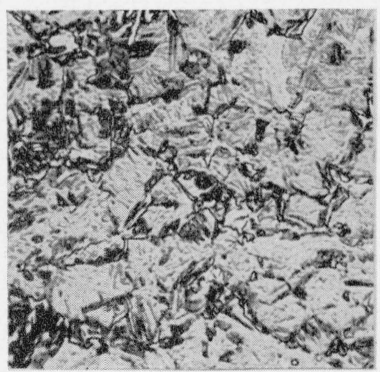

BR-17

$0.44 \% \mathrm{C}$

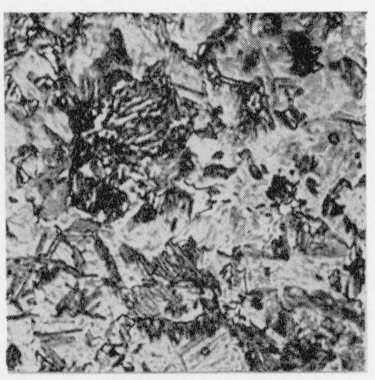

$8 R-27$

$0.49 \% \mathrm{C}$
CODE C

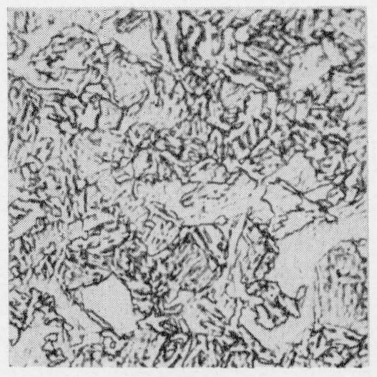

BR-23

$0.19 \%$ C

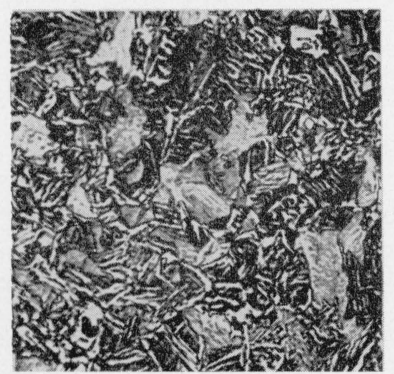

BR- 19

$0.28 \% \mathrm{C}$

Figure 6. Microstructures of pairs of steels, boron-free, slack quenched to hardness levels selected for testing.

\section{CODE B}

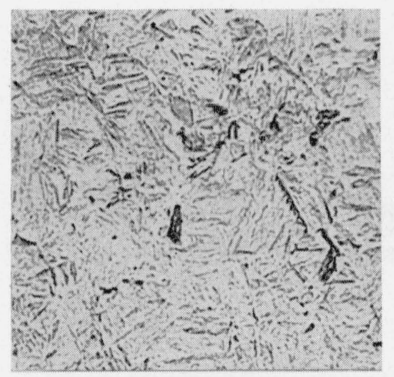

$B R-25$

$0.30 \% \mathrm{C}$

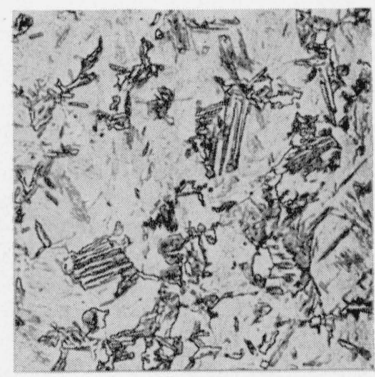

BR-1

$0.38 \% \mathrm{C}$

\section{CODE D}

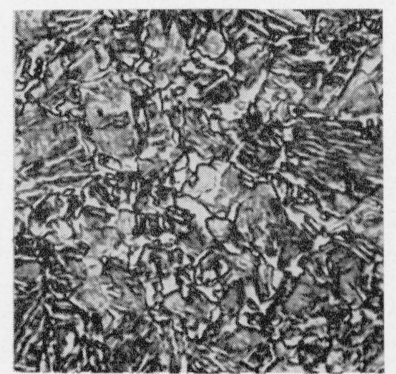

BR -25

$0.30 \% \mathrm{C}$

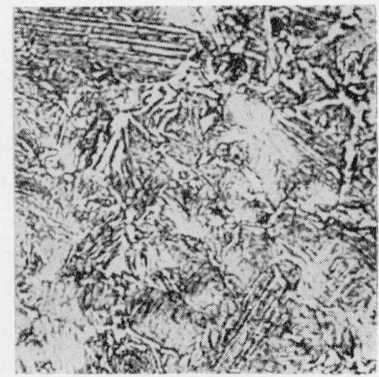

BR -27

$0.49 \%$ C 
CODE A

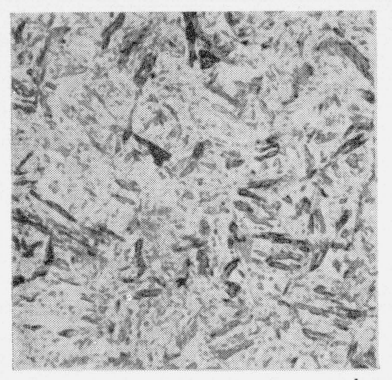

BR -18

$0.44 \%$ C

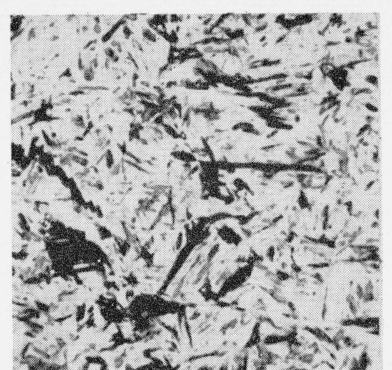

$B R-27$

$0.49 \% \mathrm{C}$

\section{CODE C}

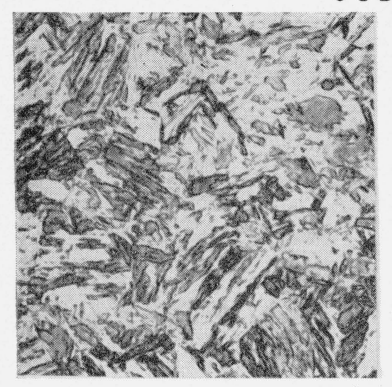

BR-24

$0.19 \%$ C

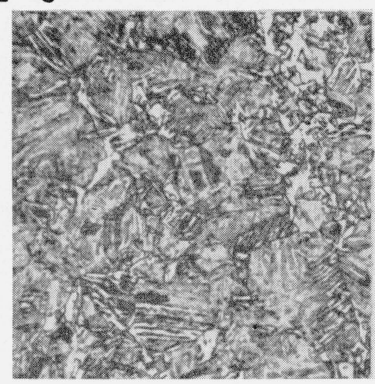

$\left(42 R_{C}\right)$

$0.28 \% \mathrm{C}$
CODE E

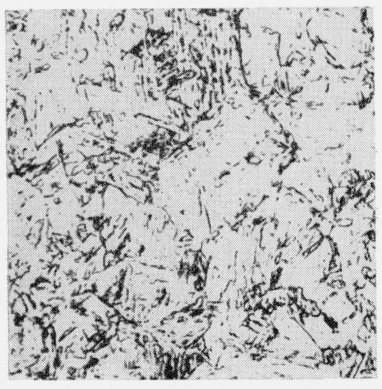

$$
B R-30 \quad\left(40 R_{C}\right)
$$

$0.19 \% \mathrm{C}$

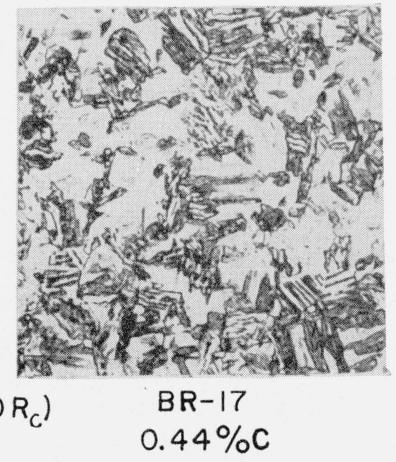

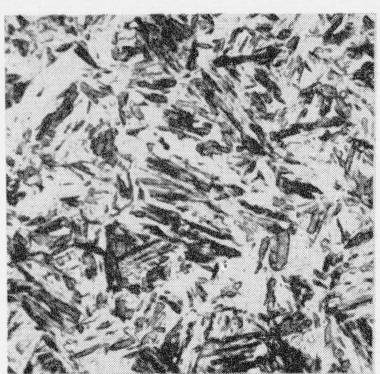

BR-26

$0.30 \% \mathrm{C}$
CODE B

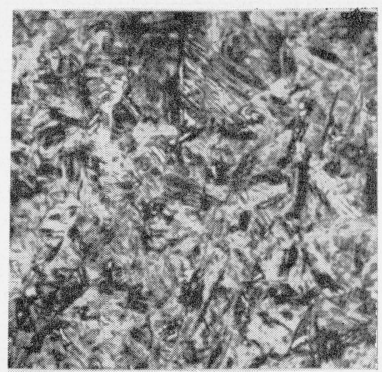

$\left(48 R_{C}\right)$

BR -17

$0.44 \% \mathrm{C}$

CODE D

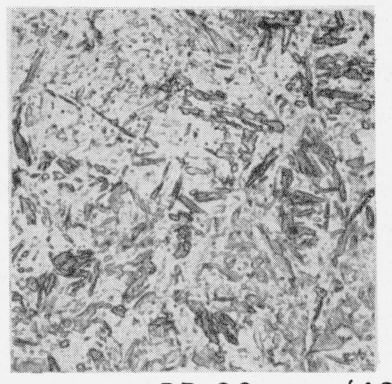

BR-20

$0.28 \% \mathrm{C}$

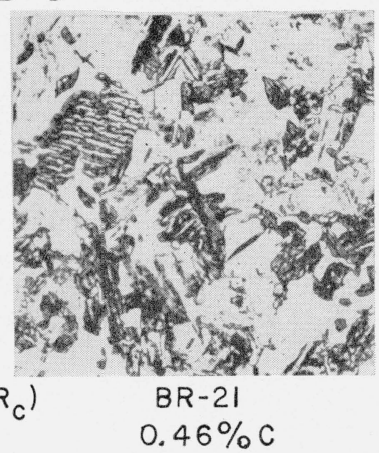

CODE $F$

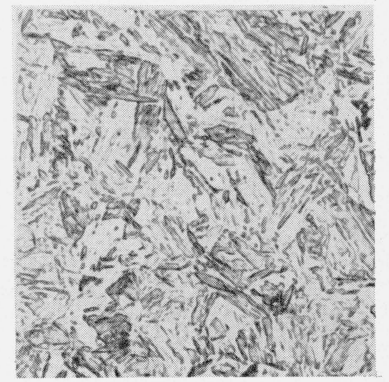

$B R-24$

O. $19 \% \mathrm{C}$

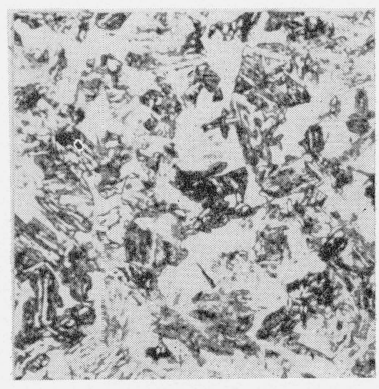

$\left(43 R_{c}\right)$
BR-2I

$0.46 \% \mathrm{C}$

FiguRE 7. Microstructures of pairs of steels, boron-treated (even numbered) and boron-free (odd numbered), slack quenched to the hardness levels selected for testing.

Etched with $1 \%$ nital. $\times 500$.

\section{Development of Heat-Treating Techniques}

\subsection{Controlled Slack Quenching}

A Jominy specimen contains an infinite number of planes parallel to the quenched end, each of theoretically constant cooling characteristics (assuming no surface cooling), and decreasing in rate of cooling with increasing distance from the quenched end. If heat loss through radiation is low in comparison with the rate of abstraction of heat from the quenched end, impact specimens should be amenable to end quenching and so develop an infinite number of planes, each uniformly cooled. With this thesis in mind, experiments were conducted to evaluate the effect of various means of end quenching impact specimens so as to develop controlled hardnesses at selected distances from the quenched end.

The root of the V-notch in a Charpy specimen is 1.08 in. (approximately $17 / 16$ in.) from each end. In steels of moderate hardenability, the hardness value obtained at $17 / 16 \mathrm{in}$. from the quenched end of a Jominy specimen usually is appreciably lower than the maximum obtainable. It was obvious, therefore, that any method that was developed for end quenching impact specimens would have to give markedly 
CODE A
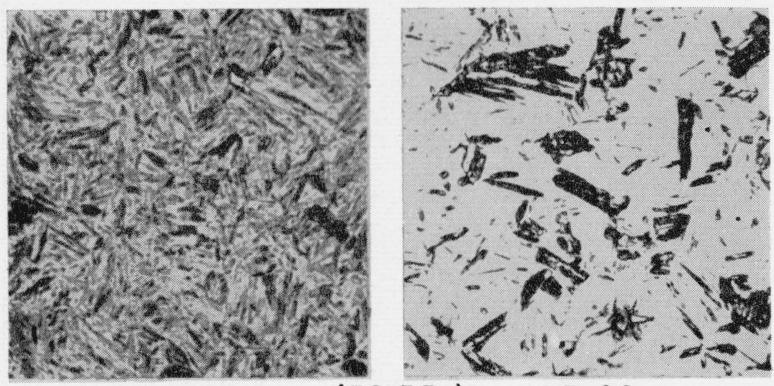

$\mathrm{BR}-18$

$0.44 \% \mathrm{C}$

$\left(52.5 R_{c}\right)$

BR-22

$0.46 \%$ C

CODE C

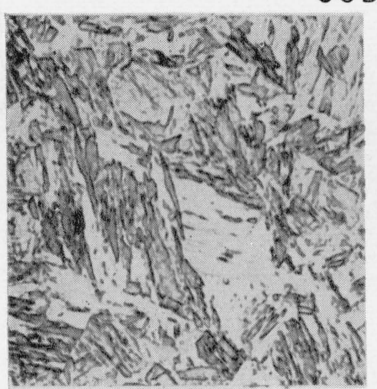

BR-24

$0.19 \% \mathrm{C}$

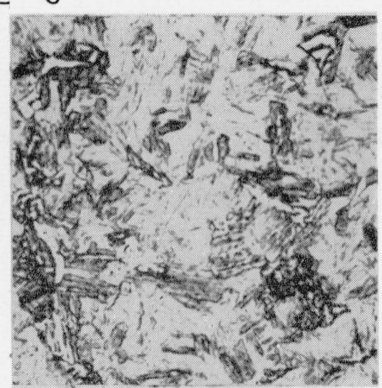

$\left(43 R_{C}\right)$

BR -26

O. $30 \% \mathrm{C}$

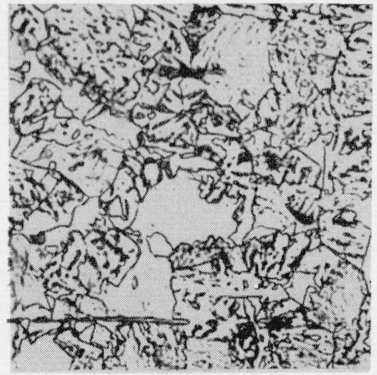

BR- 20

$0.28 \% \mathrm{C}$

$\left(30 R_{C}\right)$

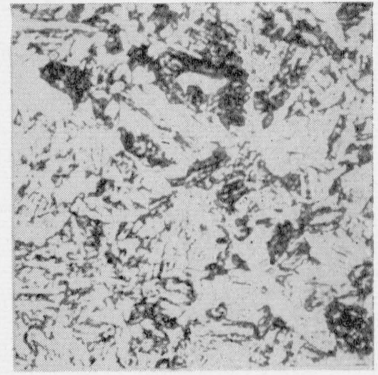

BR-18

O. $44 \% \mathrm{C}$

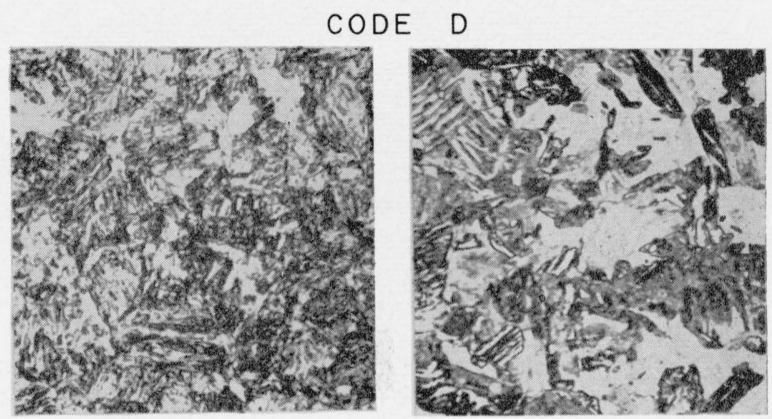

$B R-20$

$0.28 \%$ C

$\left(43 R_{C}\right)$

BR- 28

CODE F
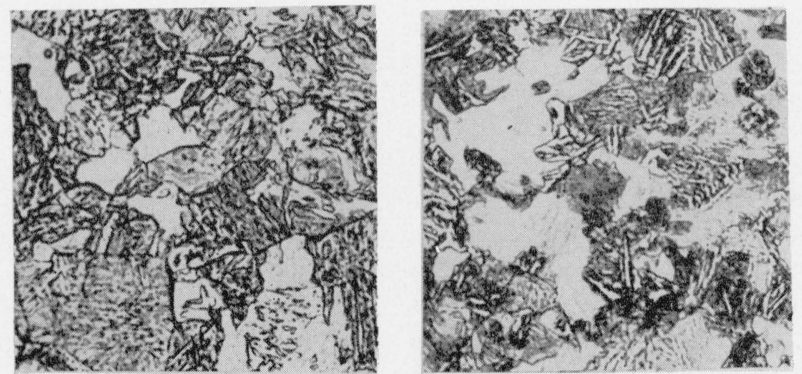

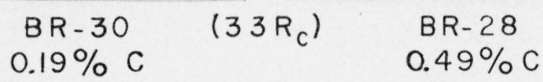

Figure 8. Microstructures of pairs of steels, boron-treated, slack quenched to the hardness levels selected for testing.

Etched with $1 \%$ nital. $\times 500$.

faster cooling rates at a distance of $17 / 16$ in. from the quenched end than that attained in the conventional Jominy specimen, if impact specimens were to be slack quenched to hardnesses only slightly below the maximum possible. Several methods to speed the rate of cooling, involving the use of various specially designed shapes and adapters, were tried, but none was completely satisfactory. The method finally adopted had the advantages of simplicity, reproducibility, and economy of material and machining. The details of this method are as follows:

The impact specimen is rough machined to approximately 0.42 in. square to allow for scaling and decarburization and to a length of $2 \%$ in. so that there will be some latitude for locating the notch.
One end is drilled and tapped to accommodate about a $1 / 4-$ in. length of a $1 / 4-20$ screw, 2 in. long. A washer, locked in a selected position by two nuts, serves to support the specimen in the quenching fixture so that a predetermined portion of the length of the specimen is immersed vertically into a still-quenching medium, which may be brine, water, or any other suitable liquid. The quenching fixture is a $1 / 4-$ in. steel plate with 8 holes $21 / 32$ in. in diameter so as to accommodate 8 specimens (fig. 9). Metal straps attached to the steel plate hold it in position above the quenching bath. After quenching, the specimens are stress relieved at $250^{\circ} \mathrm{F}$ to prevent cracking and are then ground equally on each side to 0.394 in. square, thereby 


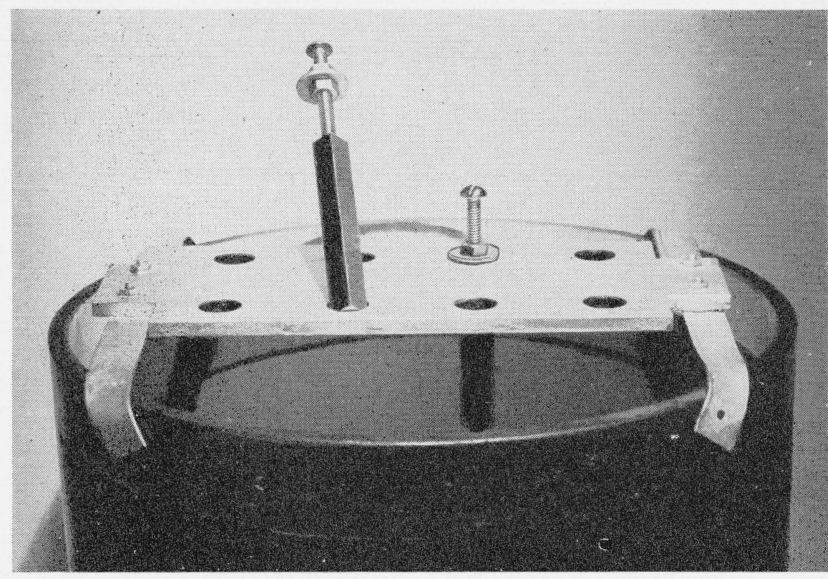

FIGURE 9. Fixture for end-immersion quenching of impact specimens,

removing any decarburization that may have occurred. A hardness survey is then made on one face to locate the exact position of the notch. This location is marked, a standard V-notch is cut into the specimen at this point, and the ends of the specimen are cut off at a distance of 1.08 in. on each side of the notch.

During the exploratory work, specimens of a commercial steel $(0.28 \%$ C, $1.6 \% \mathrm{Mn}, 0.0015 \%$ B) were end immersed to different levels, and the hardnesses and microstructures at various positions were correlated with those that existed in a standard Jominy end-quenched specimen of the same steel. Repeated hardness checks and metallographic examinations of end-immersed impact specimens showed consistently equal hardness and similar microstructures over the entire cross section of any selected plane parallel to the quenched end. Hardness surveys on impact specimens end immersed to various depths in brine, together with the Jominy curve for the same steel, are shown in figure 10. Examination of these curves indicated that any hardness (corresponding to some particular cooling rate) existing in the Jominy specimen could be duplicated by end immersing the impact specimen. The correlation between the normally end-quenched Jominy specimens and the impact specimens, immersed to different depths in brine, water, and liquid lead-bismuth alloy, is shown in figure 11.

As a result of the exploratory work described, performed on the steel noted, additional tests were conducted on one of the experimental steels. An impact specimen was end immersed into brine to a depth of $7 / 8$ in. and the hardness was measured on flats 0.015 and 0.197 in. (approximately center) below the original surface. The hardness and microstructure at both levels checked closely; the curves shown in figure 12 represent the averages of the hardness readings plotted against the distances from the quenched end. The microstructures of both the end-immersed impact specimen and of the Jominy specimen of the same steel at selected locations of equal hardness are also shown in this

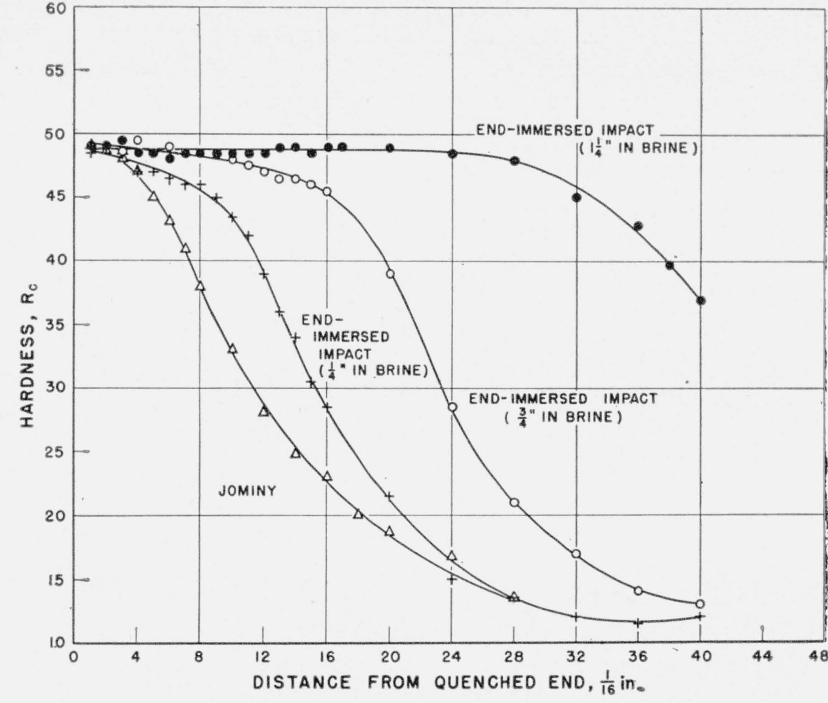

FIgURE 10. Hardenability curves obtained by end immersing impact specimens to various depths in brine compared with the standard curve obtained from a 1-in. round Jominy specimen end quenched in the conventional manner.

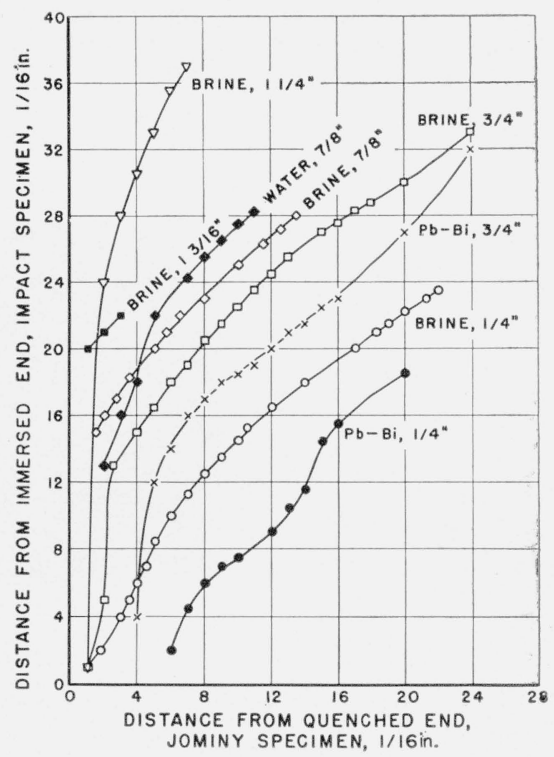

FIgURE 11. Correlation between ena-immersed impact specimens and end-quenched Jominy specimens.

The plotted points represent locations of equal hardness and, consequently, equal cooling rates. For example, assume it is desired to duplicate in an impact specimen the same hardness as that produced at $8 / 16$ in. from the quenched end of a Jominy specimen. From the curves, end immersing an impact specimen immersed end. Furthermore, immersing the impact specimens to $3 / 4 \mathrm{in}$. in brine will produce the desired hardness at 20/16 in. Temperature of the lead bismuth alloy was $300^{\circ} \mathrm{F}$.

figure. It will be noted that the microstructures at positions of equal hardness are similar and that the structure of the impact specimen at any plane of hardness is uniform from just below the surface to the center. An additional example of the uniformity of structure that exists from just below the surface to the center of an end-immersed impact specimen of another steel is shown in figure 13 . 
IMPACT SPECIMEN

$1-7$
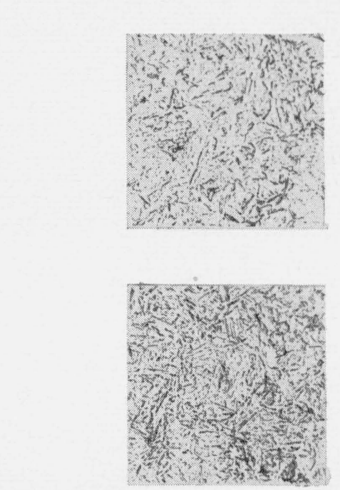

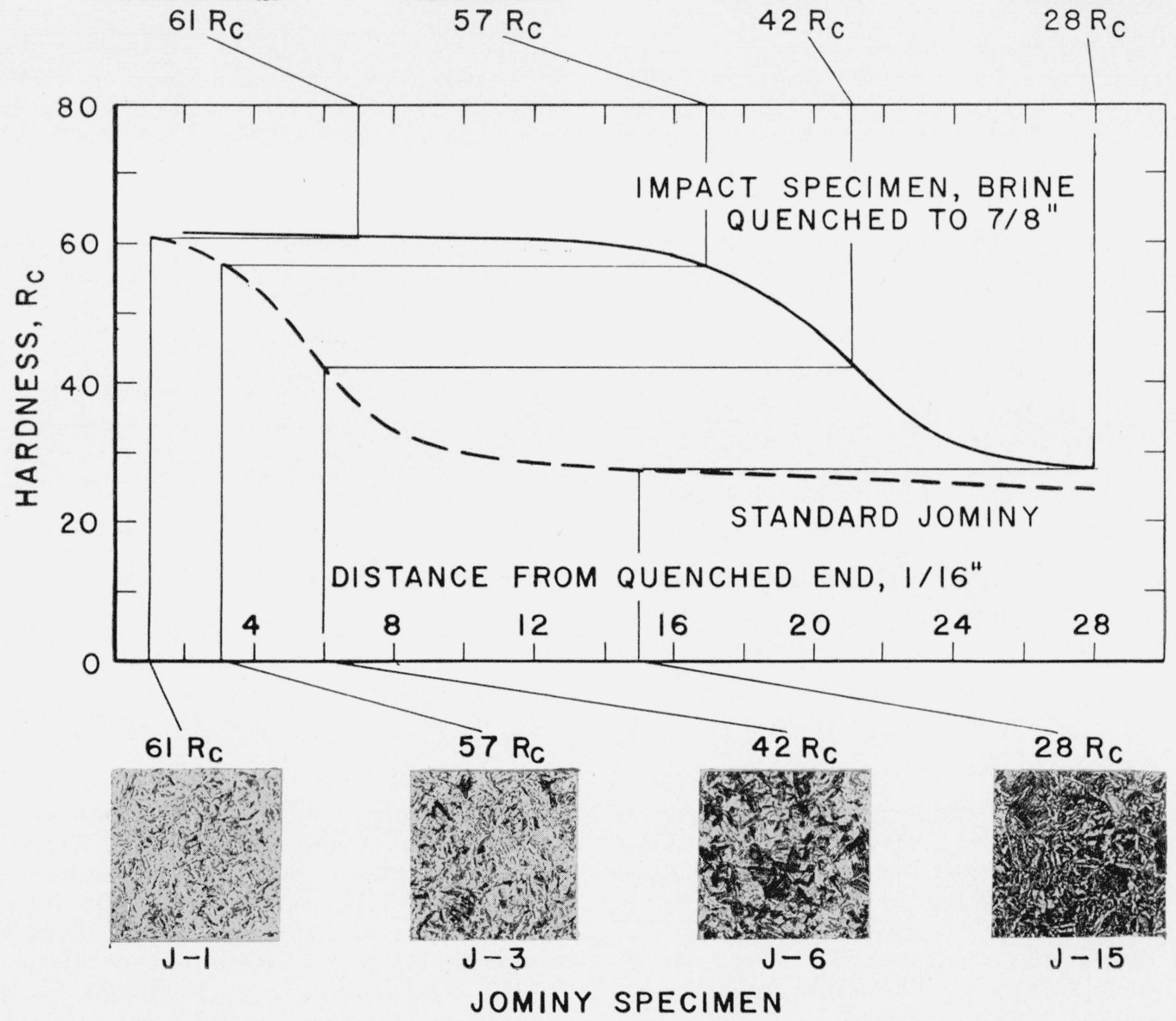

$$
1-17
$$

$0.015^{\prime \prime}$

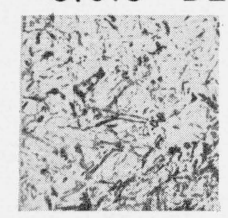

CENTER OF SPECIMEN
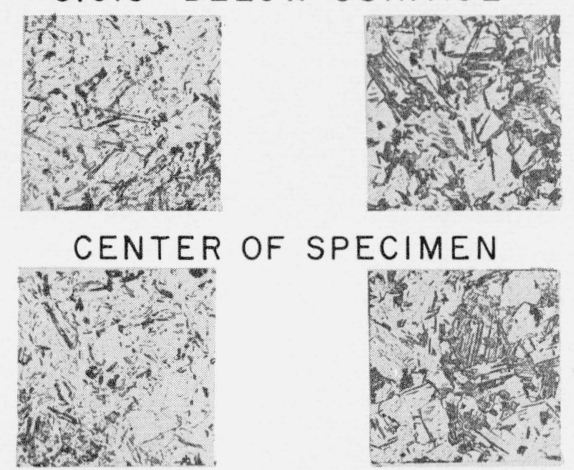

$|-2|$

$1-28$

FIGURE 12. End-quench hardenability curves and microstructures at equivalent hardness levels on a standard Jominy specimen and an end-immersed impact specimen from a single steel $(B R-21,0.46 \% C)$.

Etched with $1 \%$ nital. $\times 500$.

\subsection{Controlled Tempering}

In addition to comparing the impact properties of pairs of different steels slack quenched to the same hardness at similar cooling rates, it was desired also to compare these pairs of steels as slack quenched to the same hardness and subsequently tempered to a lower but equal hardness. It was apparent that the tempering treatments necessary to produce the desired hardness could be expected to vary from steel to steel and that comprehensive 

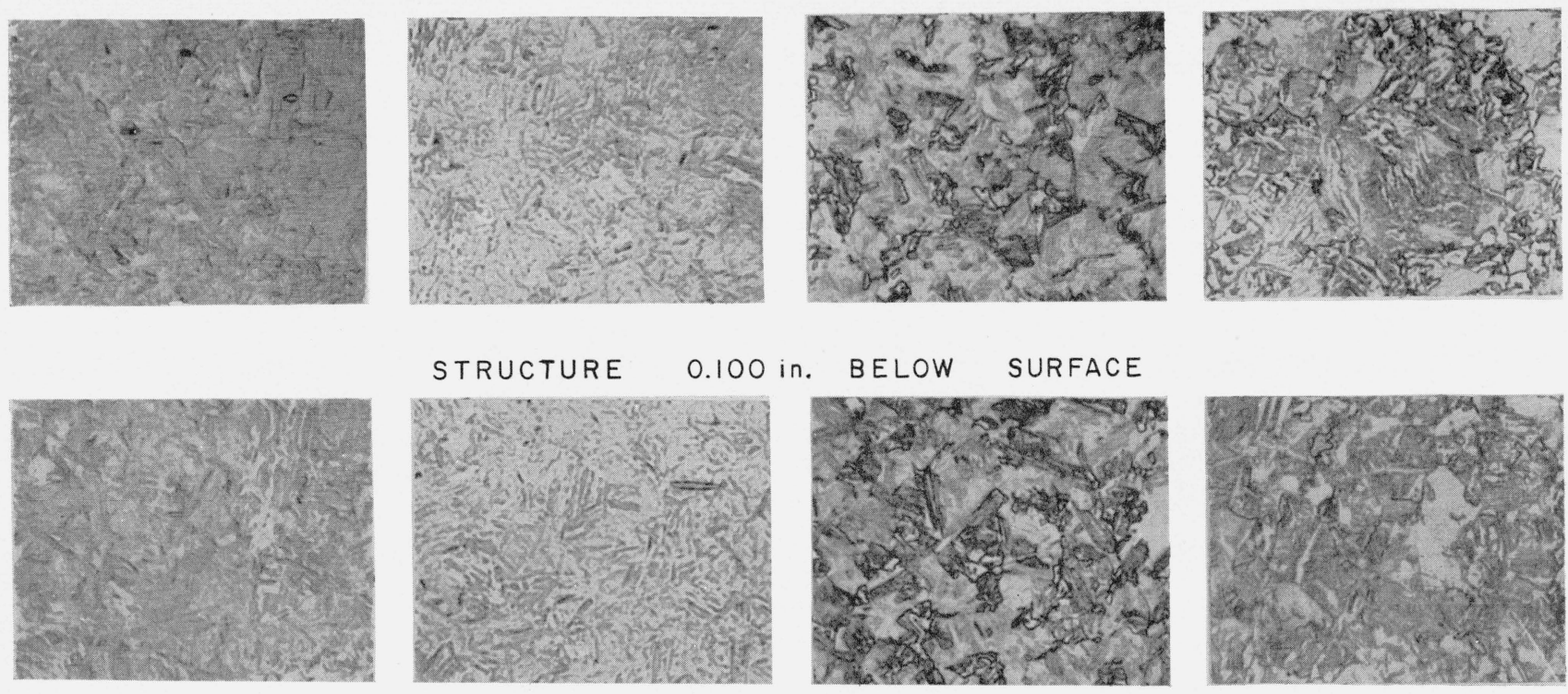

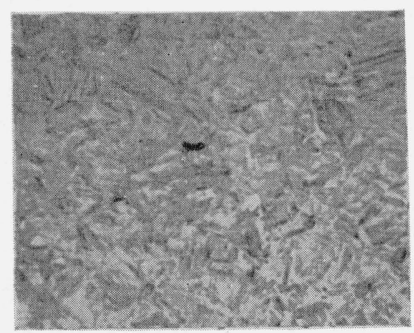

$3 / 16$ in., $\left(56 R_{c}\right)$

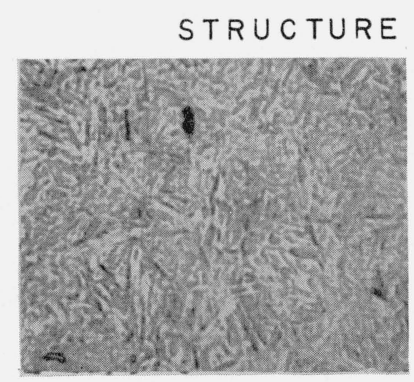

12/16 in., (5 $\left.\mid R_{c}\right)$

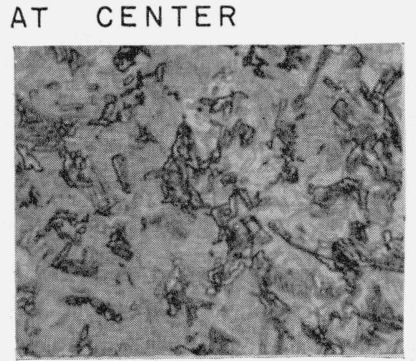

$20 / 16$ in., $\left(44 R_{c}\right)$.

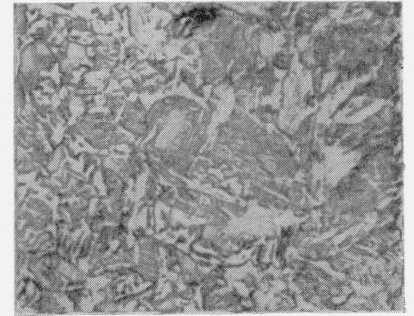

$26 / 16 \mathrm{in.},\left(30 R_{c}\right)$

\section{DISTANCE FROM IMMERSED END}

FIGURE 13. Uniformity of microstructure from just below the surface to the center and at different distances from the immersed end of an impact specimen of steel BR-17 $(0.44 \%$ C).

This specimen was end immersed to a depth of $7 / 8 \mathrm{in}$, in brine. Etched with $1 \%$ nital. $\times 500$.

data on the influence of tempering the experimental steels, therefore, would be necessary.

Impact specimens of many of the boron-free steels were end immersed in brine to a depth of $7 / 8$ in. The original surfaces were removed by grinding and a hardness determination was made every $1 / 16$ in. from the quenched end. These specimens were then tempered for $1 \mathrm{hr}$ in succession at $300^{\circ}, 400^{\circ}$, $500,^{\circ} 600,^{\circ} 700,^{\circ} 800,^{\circ} 900,^{\circ}$ and $1,000^{\circ} \mathrm{F}$ and $a$ hardness survey was made of the entire length of each specimen after each temper. A similar procedure was followed with conventionally quenched Jominy bars using a tempering time of $1 \frac{1}{2} \mathrm{hr}$ because of the larger cross section. The resulting data are presented in figures 14 and 15 . Figure 14 shows the effect of tempering up to $1,000^{\circ} \mathrm{F}$ on the maximum hardness (hardness at $1 / 16$ in. from the quenched end of the Jominy specimen) as measured on both Jominy and impact specimens. Figure 15 differs in that it shows the effect of tempering on the planes of originally equal slack-quenched hardnesses of pairs of impact specimens of the steels.

The curves of figure 15 were used as a guide for tempering the test specimens of these particular steels. These data were sufficient to serve as a general guide, subject to experimental modification, for all of the steels. After slack quenching and then stress relieving at $250^{\circ} \mathrm{F}$, the planes of equal hardness were located and the specimens were then tempered for $1 \mathrm{hr}$ at the proper temperature to give the desired hardness. The hardness of the same plane was checked in each specimen after tempering to assure that the proper hardness level had been reached. Any specimen which failed to develop the proper hardness within $\pm 1 R_{\mathrm{c}}$ (most were within less than $\pm 1 / 2 R_{c}$ ) was not used. 

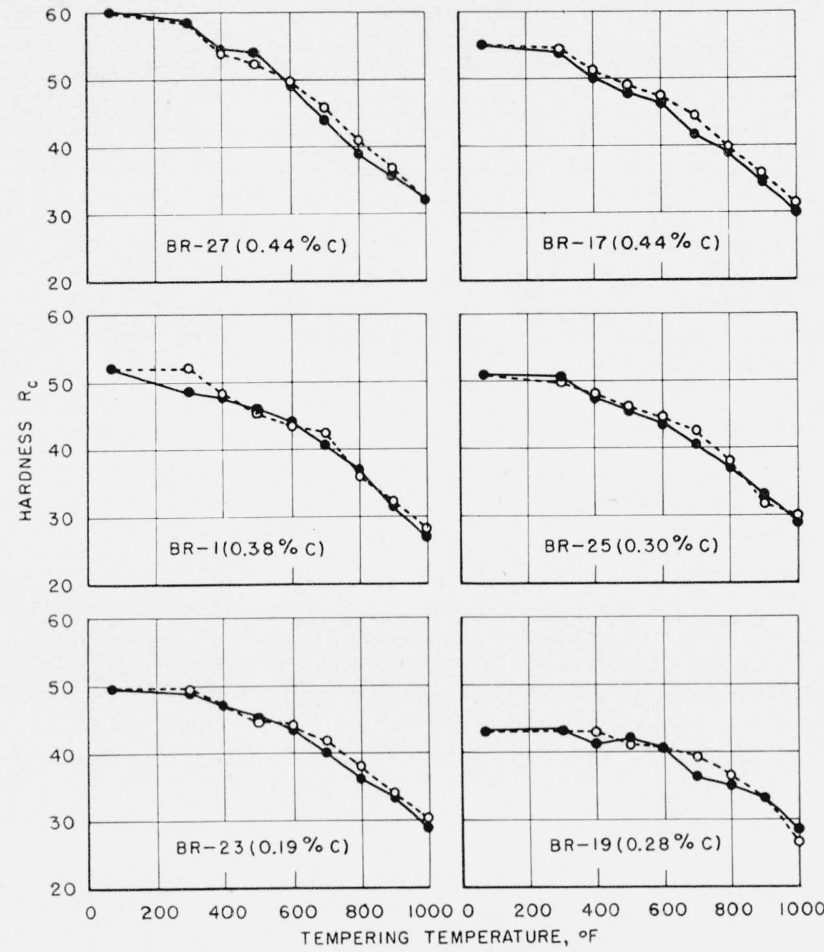

FiguRE 14. Effect of tempering temperature on maximum hardness (hardness at J-1 of the standard Jominy bar).

Solid lines represent values obtained from Jominy bars, dashed lines from impact specimens.

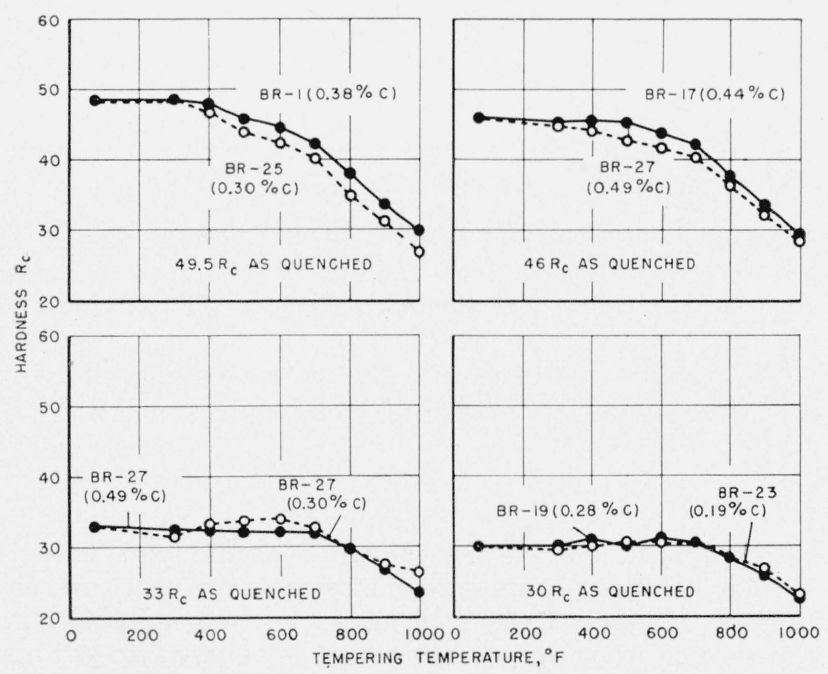

FiguRE 15. Effect of tempering temperature on the hardness of pairs of end-immersed impact bars at planes of originally equal hardnesses and cooling rates (points of intersection of their Jominy hardenability curves).

\section{Impact Tests - Results and Discussion}

\subsection{Test Procedure}

All tests were conducted in a Charpy impact testing machine of $224-\mathrm{ft}-\mathrm{lb}$ capacity. The machine conformed to ASTM specifications except for the radius of the striking edge which was $0.047 \mathrm{in}$. instead of 0.315 in. All specimens conformed to the ASTM standard for Charpy $V$-notch impact specimens (0.394 in. square times 2.165 in. long, with a $45^{\circ}$ $\checkmark$-notch, $0.079 \mathrm{in}$. deep, and a root radius of $0.010 \mathrm{in}$ ). The test temperature varied within the range of $-320^{\circ} \mathrm{F}$ to $+300^{\circ} \mathrm{F}$. Specimens tested at other than room temperature were held at the temperature of test in a liquid bath for at least $15 \mathrm{~min}$ prior to breaking, and the elapsed time between removal from the bath and breaking of the specimens was about 3 sec.

Impact tests were made on pairs of steels slack quenched at equal cooling rates to identical hardness levels. In addition, tests also were made on many of these pairs of steels as slack quenched to equal hardness levels and subsequently tempered to lower but equal hardness levels. Supplementary tests were made on some of the same steels as fully hardened and then tempered to the same hardness levels as the slack-quenched or slack-quenched and tempered steels.

The impact data obtained were plotted on two sets of graphs. The first (figs. 16 to 20) compares the impact properties of the various pairs of steels slack quenched to equal hardness, both with and without tempering. Data on the properties of any one steel, therefore, often appear in more than one graph, depending upon the combination of steels involved. In order to assess more directly the effect of slack quenching, both with and without tempering, upon the impact properties of individual steels, the data are replotted in the second set of graphs (figs. 21 to 27). Where available, data for the fully hardened steels are included.

All fractured specimens were examined to evaluate the relative amounts of brittle and ductile fracture. It was observed that the gradation in appearance of fracture from ductile to brittle was less distinct in many slack-quenched specimens than it was in fully hardened specimens. This was attributed to the mixed structures existing in the slack-quenched specimens. Consequently, quantitative determinations of the relative amounts of brittle and ductile fracture in slack-quenched specimens were difficult to make in some cases and the values obtained were believed to be only approximately correct. For this reason the data are not included in the graphs.

\subsection{Slack-Quenched Pairs of Steels}

The test data obtained on pairs of steels, slack quenched to the hardness levels indicated, and also as slack quenched and tempered, are given in figures 16 to 20 , inclusive. The hardness at which each 


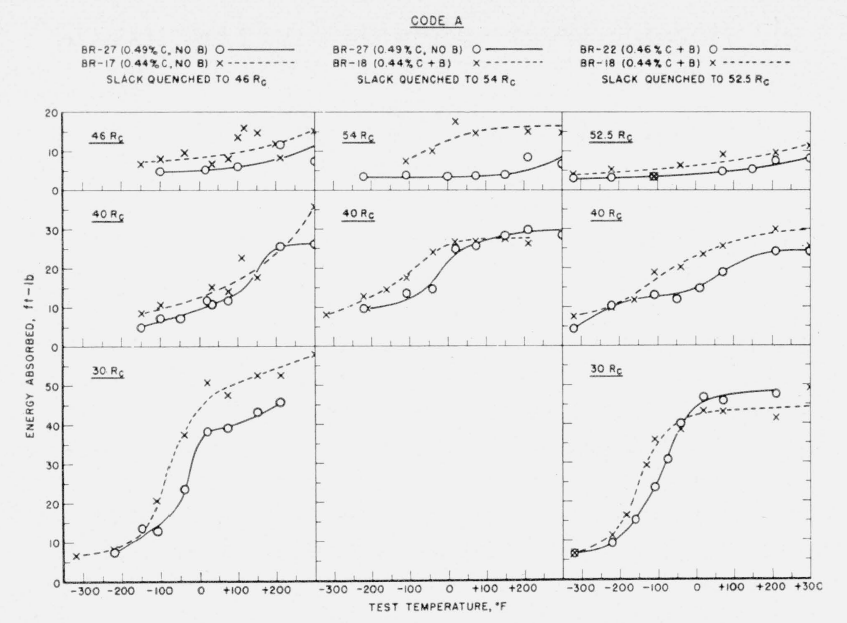

FIGURE 16. Impact strengths of slack-quenched pairs of steelsCode $A$.

The underlined hardness number in each block indicates the hardness of the steels, as quenched. The lower hardnesses were obtained by tempering the slack-quenched steels. Maximum hardness: BR-27, $60 \mathrm{R}_{\mathrm{c}} ; \mathrm{BR}-22,58 \mathrm{R}_{\mathrm{c}} ; \mathrm{BR}-17$, $55 \mathrm{R}_{\mathrm{c}} ; \mathrm{BR}-18,551 / 2 \mathrm{R}_{\text {。 }}$

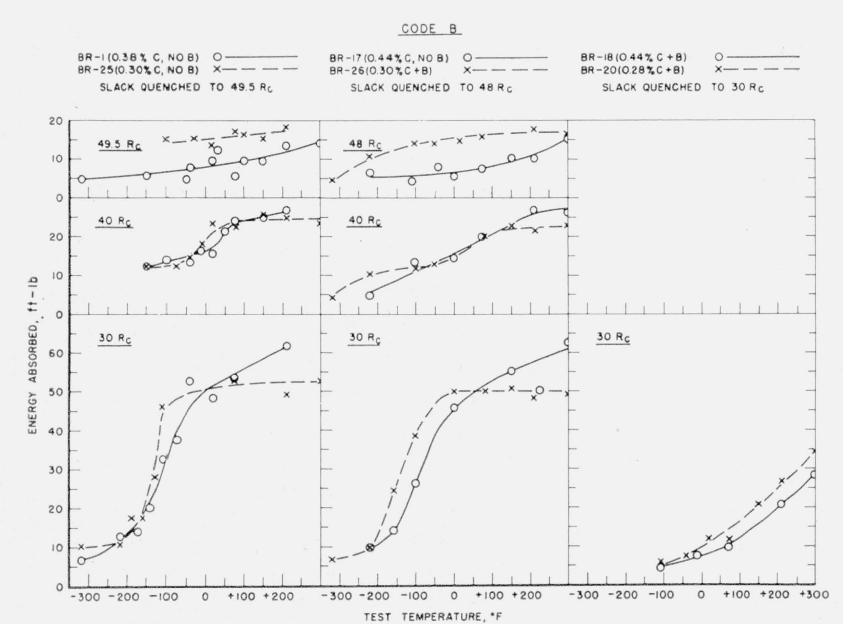

FIGURE 17. Impact strengths of slack-quenched pairs of steelsCode B.

The underlined hardness number in each block indicates the hardness of the steels. The lower hardnesses were obtained by tempering the slack-quenched steels. Maximum hardness: $\mathrm{BR}-17,55 \mathrm{R}_{\mathrm{c}} ; \mathrm{BR}-18,551 / 2 \mathrm{R}_{\mathrm{e}} ; \mathrm{BR}-1,52 \mathrm{R}_{\mathrm{c}}$ $\mathrm{BR}-25,501 / 2 \mathrm{R}_{\mathrm{c}} ; \mathrm{BR}-26,511 / 2 \mathrm{R}_{\mathrm{c}} ; \mathrm{BR}-20,491 / 2 \mathrm{R}_{\mathrm{c}}$.

pair of steels was tested is indicated in the various blocks by the underlined value. Each figure gives the complete data for a single combination as indicated by the code thereon and includes, where available, a nonboron versus a nonboron steel (left column), a nonboron versus a boron steel (center column), and a boron versus a boron steel (right column). Because of variations in melting, the carbon contents often varied slightly from the desired values.

A significant observation to be made from these figures is that the lower carbon steel of any pair

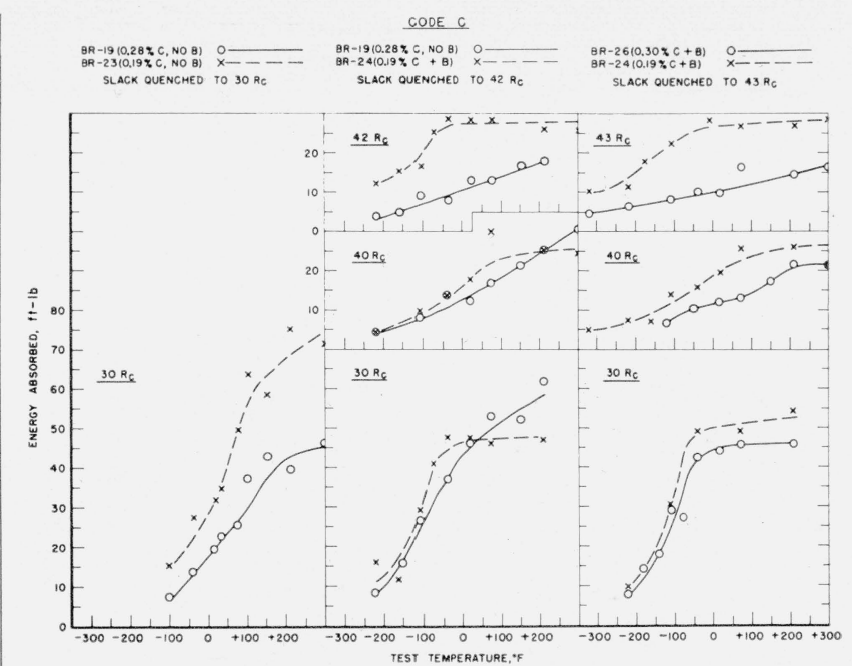

FIGURE 18. Impact strengths of slack-quenched pairs of steelsCode $C$.

The underlined hardness number in each block indicates the hardness of the steels. The lower hardnesses were obtained by tempering the slack-quenched steels. Maximum hardness: BR-26, 51 1/2 R ; BR-19, 49 1/2 R $\mathrm{R}_{\mathrm{c}}$; BR-23, $43 \mathrm{R}_{\mathrm{c}}$; steels. Maximum

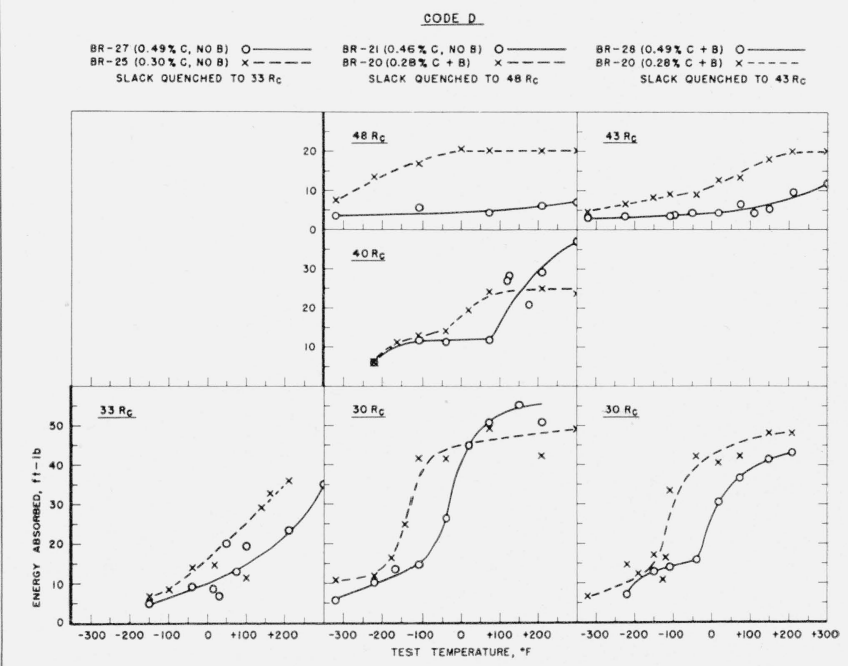

FIGURE 19. Impact strengths of slack-quenched pairs of steels Code D. The underlined hardness number in each block indicates the hardness of the
steels. The lower hardnesses were obtained by tempering the slack-quenched steels. The lower hardnesses were obtained by tempering the slack-quenched
steels. Maximum hardness: BR-27, $60 \mathrm{R}_{\mathrm{c}}$; B R-28, $60 \mathrm{R}_{\mathrm{c}} ; \mathrm{BR}-21,59 \mathrm{R}_{\mathrm{c}}$; B R-25, steels. Maximum hardness:
$501 / 2 \mathrm{R}_{\mathrm{c}} ; \mathrm{BR}-20,491 / 2 \mathrm{R}_{\mathrm{c}}$.

slack quenched to the same hardness invariably showed impact properties superior to that of the higher carbon steel, regardless of whether or not boron was present. With but one or two exceptions, where the differences in the impact curves were slight, this superiority was maintained after tempering the slack-quenched pairs.

The degree of difference in impact properties noted between the individual steels of each slack-quenched pair was usually greatest in the as-slack-quenched 


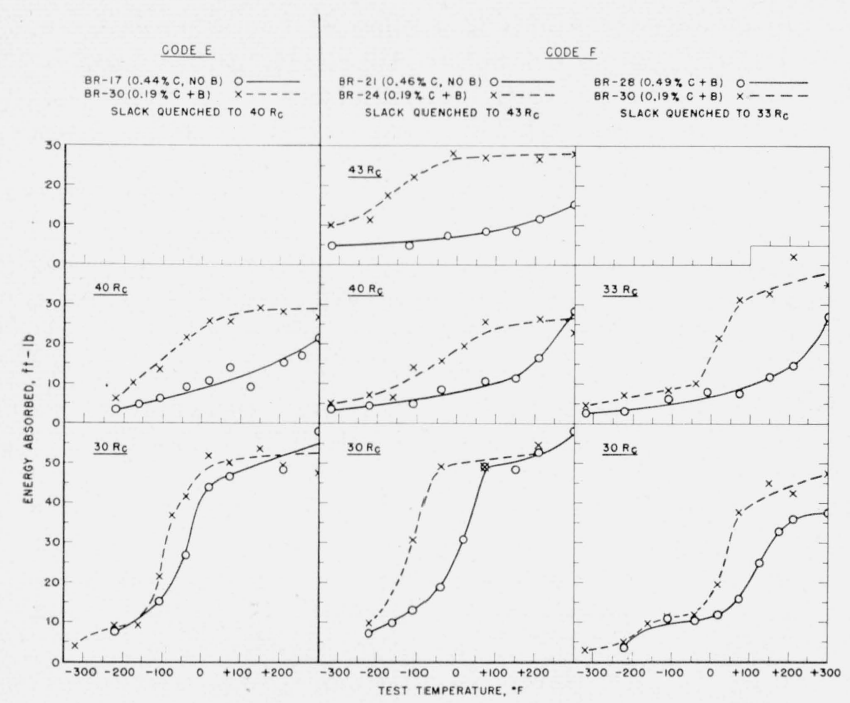

FIGURE 20. Impact strengths of slack-quenched pairs of steelsCode $E$ and Code F.

The underlined hardness number in each block indicates the hardness of the steels. The lower hardnesses were obtained by tempering the slack-quenched steels. Maximum hardness: BR-28, $60 \mathrm{R}_{\mathrm{c}}$; BR-21, $59 \mathrm{R}_{\mathrm{c}}$; BR-17, $55 \mathrm{R}_{\mathrm{c}}$; B R-30 $43 \mathrm{R}_{\mathrm{c}}$; $\mathrm{BR}-24,431 / 2 \mathrm{R}_{\mathrm{c}}$.

condition; tempering generally reduced the difference between the steels in each pair. The extent of the initial difference in impact properties of the as-slackquenched steels was related to the difference in carbon content of the steels in each pair; i. e., the greater the difference in carbon, the greater the difference in impact properties. Tempering, generally, raised the impact strength levels of the pairs, particularly at the higher and intermediate temperatures of test. This resulted in the establishment of a more pronounced transition from ductile to brittle fracture.

It must be emphasized that, because of the desigh of the experimental steels, the total alloy contents varied inversely with the carbon contents and that the higher amount of alloy in the lower carbon steels may be a factor in the better impact properties shown by these steels. To separate these two variables would have necessitated melting additional series of steels not contemplated in the original plan of the investigation.

\subsection{Evaluation of Effect of Slack Quenching Upon the Impact Properties}

The effect of slack quenching upon the impact strength of the steels at certain hardness levels is shown in figures 21 to 27, inclusive. Each figure (except fig. 27) presents all the impact data on each split heat tested, both without and with boron. Figure 27 gives data on two steels not from the same heat (BR-1 and BR-30). Data are given for each steel as slack quenched to the hardness indicated, and as slack quenched and tempered. For comparison, data also are given, where available, on the properties of the steels as fully hardened and then tempered to the required hardness level.
The impact properties of the untempered slackquenched steels were lower the higher the hardness to which the steels were slack quenched. This was attributed to the greater quantity of untempered martensite present in the harder steels. Upon tempering, however, this order was reversed and the steels originally slack quenched to the higher hardness levels had impact properties superior to the same steels originally slack quenched to the lower hardness levels, thus indicating the deleterious effect of slack quenching. This was attributed to the larger amounts of tempered martensite present in the steels originally slack quenched to the higher hardnesses. The steels originally slack quenched to the lower hardnesses contained less martensite that could be toughened by tempering, and more ferrite and pearlite; the two latter constituents are not appreciably toughened by tempering.

As an illustration of the trends just described, attention is directed to the data for steel BR-17 (fig. 23). This steel was slack quenched to three levels of hardness, $R_{c} 48,46$, and 40 . Examination of the curves indicates that the impact properties improved slightly as the slack-quenched hardness decreased. When tempered to 40 and $30 R_{c}$, however, the impact properties of the steels originally slack quenched to $48 \mathrm{R}_{\mathrm{c}}$ were better than those slack quenched to $46 \mathrm{R}_{\mathrm{c}}$, which, in turn, were better than those slack quenched to $40 \mathrm{R}_{\mathrm{c}}$. Another illustration

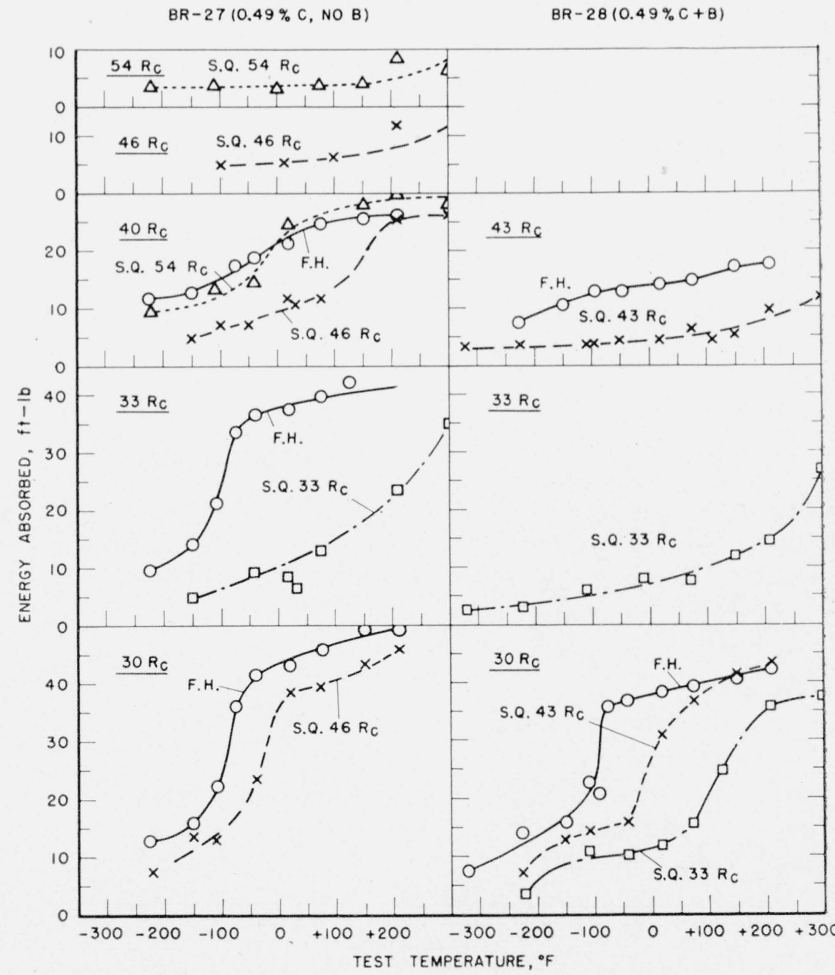

Figure 21. Impact strengths of the $0.49 \% \mathrm{C}$ steels.

The underlined hardness number in each block indicates the hardness of the steel. The hardness number on each curve indicates the original slack-quenched hardness. Where the underlined hardness is less than the slack-quenched hardness, the specimens have been tempered. S. Q. equals slack quenched. F. H equals fully hardened. As fully hardened, both steels had an original hardness of $60 \mathrm{R}$. 
$B R-21(0.46 \%$, NOB)

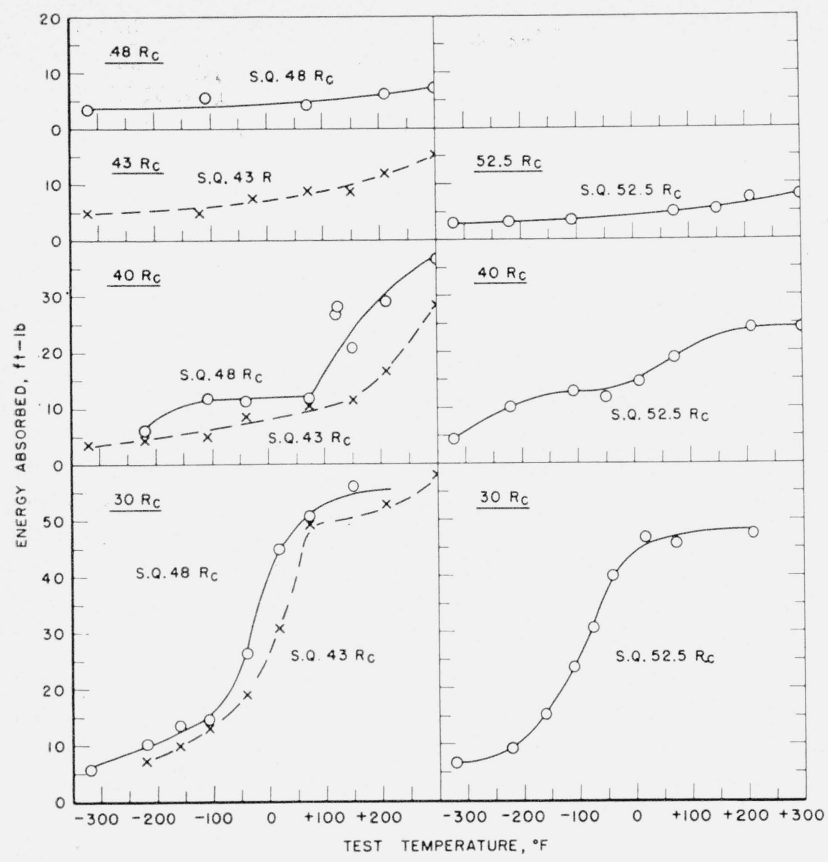

Figure 22. Impact strengths of the $0.46 \% \mathrm{C}$ steels.

The underlined hardness number in each block indicates the hardness of the steel. The hardness number on each curve indicates the original slack-quenched hardness. Where the underlined hardness is less than the slack-quenched hardness, the specimens have been tempered. S. Q. equals slack quenched. No tests were made on steels $\mathrm{BR}-21$ and $\mathrm{BR}-22$ as initially fully hardened but in this condition the hardness was 59 and $58 \mathrm{R}_{c}$, respectively.

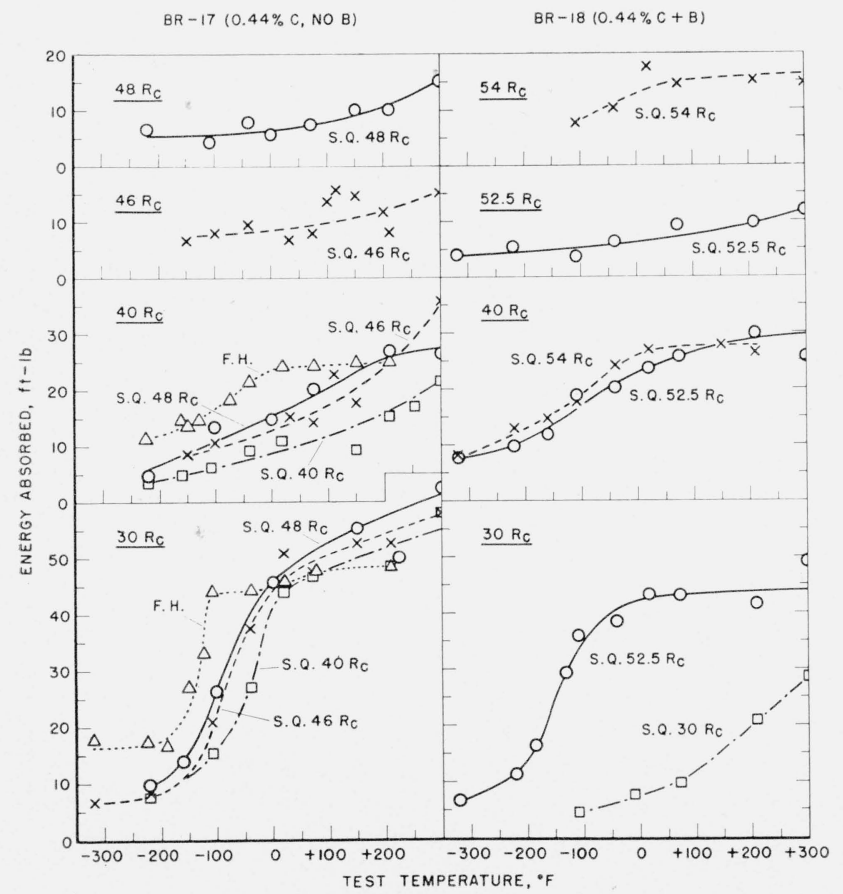

Figure 23. Impact strengths of the $0.44 \% \mathrm{C}$ steels.

The underlined hardness number in each block indicates the hardness of the steel. The hardness number on each curve indicates the original slack-quenched hardness. Where the underlined hardness is less than the slack-quenched hardness, the specimens have been tempered. S. Q. equals slack quenched. F. H. equals fully hardened. As fully hardened, $\mathrm{BR}-17$ had an initial hardness of $55 \mathrm{R}_{\mathrm{e}}$. No tests were made on BR-18 as initially fully hardened, but in this condition its hardness was $551 / 2 \mathrm{R}_{\mathrm{c}}$ of this trend is shown in figure 21 for steel BR-28. As initially slack quenched to $33 \mathrm{R}_{\mathrm{c}}$ and tested at that hardness, the impact properties were somewhat superior to those of the same steel initially slack quenched to $43 \mathrm{R}_{\mathrm{c}}$, and tested at that hardness. However, after tempering both to $30 \mathrm{R}_{\mathrm{c}}$, the steel initially slack quenched to the higher hardness had the better impact properties. When the original slack-quenched hardness was relatively high, thus indicating only a small amount of nonmartensitic products in the microstructure, the deleterious effect of slack quenching upon the impact properties was small. This is illustrated by steel BR-27 (fig. 21) tested at $40 \mathrm{R}_{\mathrm{c}}$. As slack quenched to $54 \mathrm{R}_{\mathrm{c}}$ and then tempered to $40 \mathrm{R}_{\mathrm{c}}$, the steel showed slightly inferior impact properties only below $0^{\circ} \mathrm{F}$ as compared with the fully hardened (original hardness equals $60 \mathrm{R}_{\mathrm{c}}$ ) and tempered steel. The same trend was shown by many of the other steels.

Thus, at any particular hardness, the fully hardened and tempered steels were usually superior to the slack quenched and tempered steels. In some cases, however, they were only equal, or even slightly inferior to the slack-quenched steels over a portion of the testing range.

The boron and nonboron steels showed one significant difference in their reaction to tempering in the

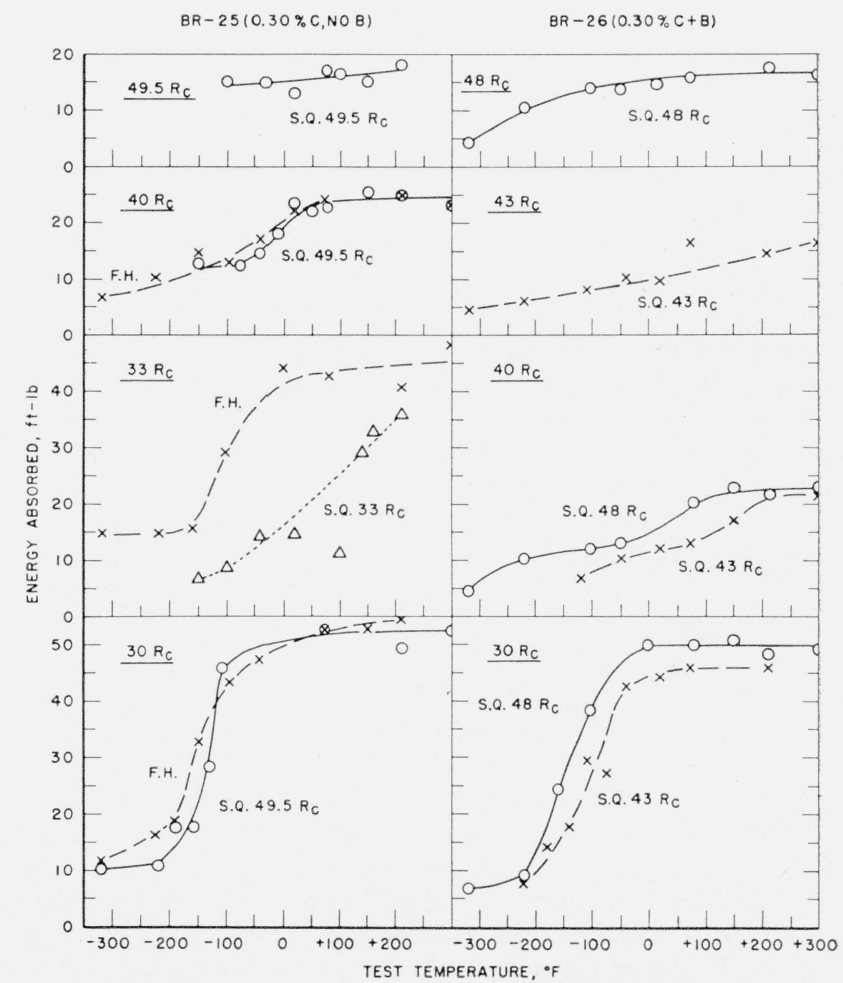

Figure 24. Impact strengths of the $0.30 \% \mathrm{C}$ steels.

The underlined hardness number in each block indicates the hardness of the steel. The hardness number on each curve indicates the original slack-quenched hardness. Where the underlined hardness is less than the slack-quenched hard ness, the specimens have been tempered. S. Q. equals slack quenched. F. H equals fully hardened. As fully hardened, BR-25 had an original hardness of

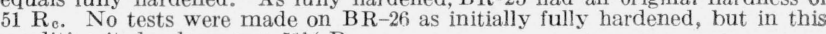
condition its hardness was $511 \frac{1}{2} \mathrm{R}$. . 


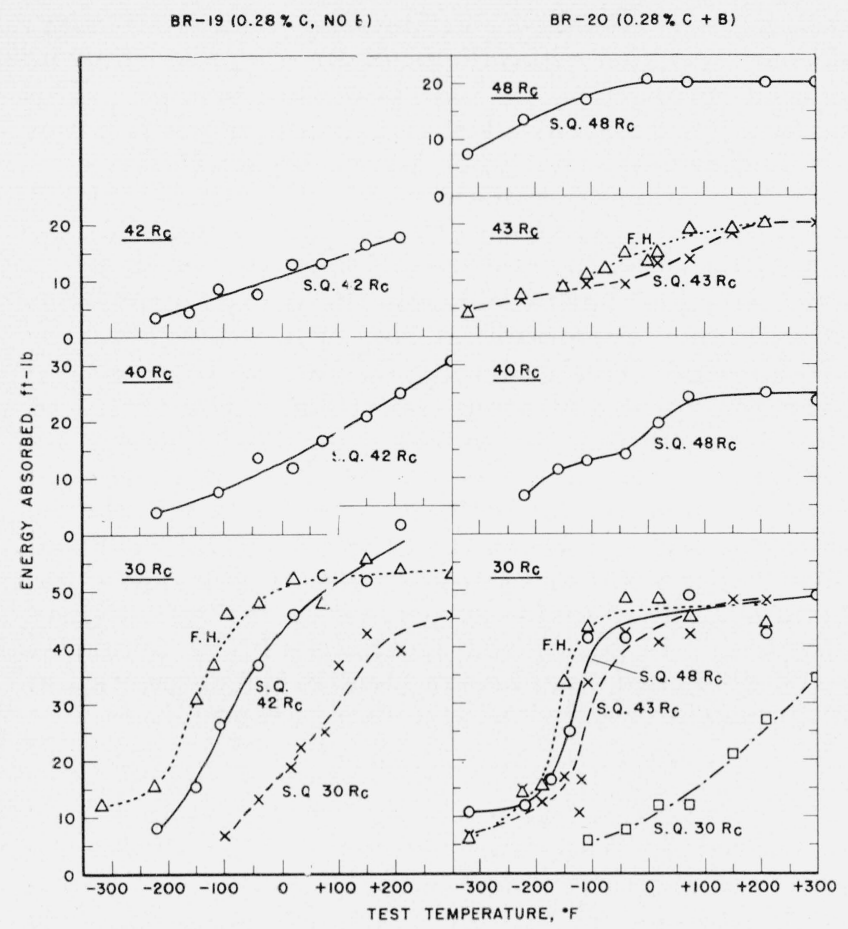

Figure 25. Impact strengths of the $0.28 \% \mathrm{C}$ steels.

The underlined hardness number in each block indicates the hardness of the steel. The hardness number on each curve indicates the original slack-quenched hardness. Where the underlined hardness is less than the slack-quenched hardness, the specimens have been tempered. S. Q. equals slack quenched. F. H $491 / 2 R_{c}$.

as-slack-quenched condition. The impact properties of the slack-quenched nonboron steels were practically always improved by tempering. Whether or not the slack-quenched boron steels were improved by tempering depended on the differential between the hardness as slack quenched and as slack quenched and tempered. When this differential was only a few points Rockwell $\mathrm{C}$, tempering to $40 \mathrm{R}_{\mathrm{c}}$ actually caused a slight deterioration in the impact properties or, at best, no change. When, however, the differential was large, tempering to either $40 R_{c}$ or 30 $\mathrm{R}_{\mathrm{c}}$ caused a definite improvement. Examples of this phenomenon can be seen in figures $24,25,26$, and 27 .

\section{Summary and Conclusions}

A method was developed and is described for heattreating impact specimens so as to produce uniform and accurately controlled slack-quenched microstructures and hardnesses at the locations where the notches are to be placed. This technique, which should prove of considerable use in the study of steels, is a modified end-quench procedure.

A group of steels, based on the $81 \mathrm{xx}$ series, varying in carbon from 0.19 to 0.49 percent, and with the alloy content adjusted at a constant ratio so as to raise the hardenability of the lower carbon steels and lower the hardenability of the higher carbon steels, was melted and fabricated. Each heat was split during pouring and boron was added to onehalf of the melt. Jominy hardenability tests were

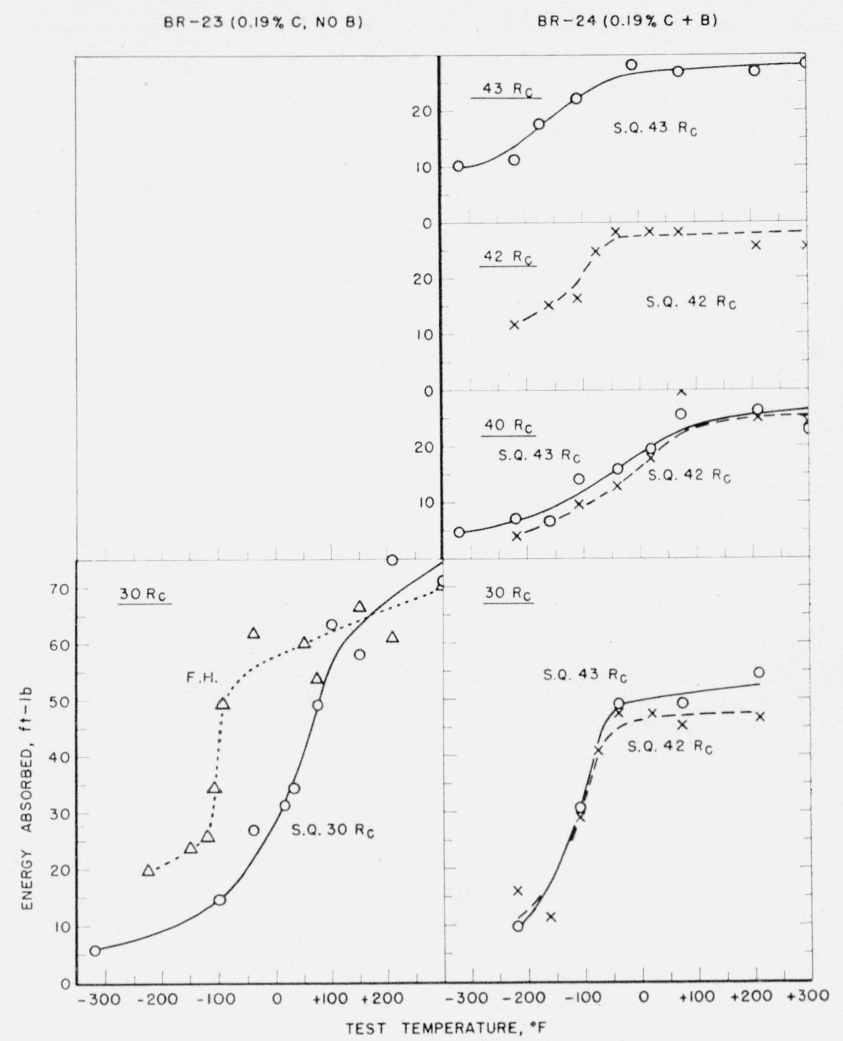

FIGURE 26. Impact strengths of the $0.19 \% \mathrm{C}$ steels.

The underlined hardness number in each block indicates the hardness of the steel. The hardness number on each curve indicates the original slack-quenched hardness. Where the underlined hardness is less than the slack-quenched hardness, the specimens have been tempered. S. Q. equals slack quenched. F. H. equals fully hardened. As fully hardened, $\mathrm{BR}-23$ had an original hardness of $44 \mathrm{R}_{\mathrm{c}}$. No tests were made on BR-24 as initially fully hardened, but in this condition its hardness was $431 / 2 \mathrm{R}_{\mathrm{e}}$.

made on all steels and the distances from the quenched ends at which the hardenability curves of various pairs of steels intersected were determined. Impact tests were made on Charpy V-notch specimens of pairs of steels slack quenched to the hardness corresponding to the intersection of their respective Jominy curves, both as slack quenched and also as subsequently tempered. The impact properties of some of the slack-quenched steels were compared with their fully hardened and tempered counterparts.

On the basis of the data obtained, the following conclusions can be drawn:

1. When slack quenched at equal cooling rates to equal hardnesses and tested at those hardness levels, the impact properties of the higher carbon lower alloy steel of a pair were always inferior to those of the lower carbon higher alloy steel, regardless of whether or not boron was present. The greater the difference in carbon and alloy content, the greater was the difference in impact properties. Tempering generally reduced the difference between the impact properties and also raised the values.

2 . The hardness level to which any individual steel was slack quenched influenced its impact properties markedly. As slack quenched only, the 


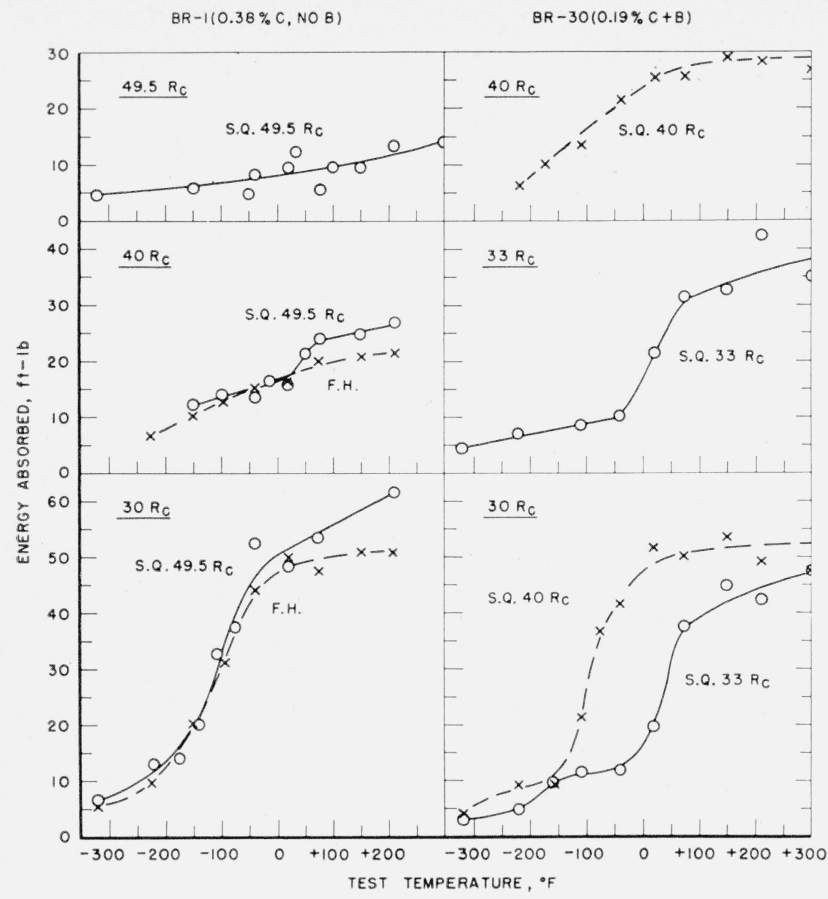

Figure 27. Impact strengths of the two steels designated.

The underlined hardness number in each block indicates the hardness of the steel. The hardness number on each curve indicates the original slack-quenched hardness. Where the underlined hardness is less than the slack-quenched hardness, the specimens have been tempered. S. Q. equals slack quenched. F. H equals fully hardened. As fully hardened, $\mathrm{BR}-1$ had an original hardness of $52 R_{\text {c }}$. No tests were made on BR-30 as initially fully hardened, but in this condition its hardness was $43 \mathrm{R}_{\mathrm{c}}$.

higher the hardness, the lower were the impact properties. Tempering, however, reversed this order in that the steels originally slack quenched to a higher hardness and then tempered to a lower hardness had impact properties superior to those of the same steels originally slack quenched to a lower hardness and then tempered.

3 . The impact properties of the slack-quenched boron steels were improved by tempering to $40 \mathrm{R}_{\mathrm{c}}$ only when the differential between the hardness as slack quenched and as slack quenched and tempered was large. When this differential was small, tempering actually caused a slight deterioration in impact properties, or, at best, no change. The impact properties of all of the slack-quenched boron steels were improved upon tempering to $30 \mathrm{R}_{\mathrm{c}}$.

4. The impact properties of all slack-quenched steels as tempered to $40 \mathrm{R}_{\mathrm{c}}$ were considerably improved when the steels were tempered to $30 R_{c}$.

5. At equal hardness levels the impact properties of the slack-quenched steels, either tempered or untempered, were generally inferior to those of the fully hardened and tempered steels. The extent of the deterioration in impact properties caused by slack quenching depended on the differential between the hardness of the steel as fully hardened and as slack quenched. When the tempered slack-quenched steel had an initial hardness close to the maximum possible, the impact properties were but slightly affected. As the initial hardness of the tempered slack-quenched steel became lower, the deterioration in impact properties became more pronounced.

The investigation reported in this paper was sponsored by Watertown Arsenal. The authors are particularly grateful to Stuart V. Arnold, of Watertown Arsenal, whose advice and criticism aided so materially in the progress of the work. The authors also are deeply appreciative of the conscientious assistance of Thomas P. Royston throughout the entire course of the investigation and of Nesbit L. Carwile, who assisted materially in the latter phases of the work.

\section{References}

[1] John Vajda and Paul E. Busby, Transverse mechanical properties of slack-quenched and tempered wrought steel, Trans. Am. Soc. Metals 46, 1,331 (1954).

[2] John Vajda and Paul E. Busby, Effect of composition on transverse properties of slack-quenched steel, Trans. Am. Soc. Metals 47, 408 (1955).

[3] Metals Handbook, American Society for Metals, Cleveland, 500 (1948).

[4] Tentative method of end-quench test for hardenability of steel (A255-48T), Am. Soc. Testing Materials, Standards, 636 (1955).

Washington, April 8, 1957. 